\title{
Design of Specific Serine Protease Inhibitors Based on a Versatile Peptide Scaffold: Conversion of a Urokinase Inhibitor to a Plasma Kallikrein Inhibitor
}

Peng Xu ${ }^{1}$, Mingming Xu ${ }^{2}$, Longguang Jiang ${ }^{2}$, Qinglan Yang ${ }^{1}$, Zhipu Luo ${ }^{3}$, Zbigniew Dauter $^{3}$, Mingdong Huang ${ }^{2}$ and Peter A. Andreasen ${ }^{*}$

${ }^{1}$ Danish-Chinese Centre for Proteases and Cancer, Department of Molecular Biology and Genetics, Aarhus University, Denmark;

${ }^{2}$ Danish-Chinese Centre for Proteases and Cancer, Fujian Institute of Research on the Structure of Matter, Chinese Academy of Sciences, Fuzhou, China;

${ }^{3}$ Synchrotron Radiation Research Section, Macromolecular Crystallography Laboratory, National Cancer Institute, Argonne National Laboratory, Argonne, USA

\section{Contents}

1. Additional Experimental Sections

2. All the peptide sequences and the $K_{i}$ values to tested proteases

3. Figures with sensorgrams from SPR analysis

4. Crystallographic parameters

5. Other supplemental figures and tables

6. References

7. HPLC chromatograms and Mass spectra of all peptides 


\section{ADDITIONAL EXPERIMENTAL SECTIONS}

\section{Determination of $K_{M}$ values}

To determine the $K_{\mathrm{M}}$ values for hydrolysis of the chromogenic substrate S-2302 by different variants of $\mathrm{hPK}$ and $\mathrm{mPK}$, a $200 \mu \mathrm{L}$ 2-fold dilution series of the substrates $(0-4 \mathrm{mM})$ in a buffer of $10 \mathrm{mM}$ HEPES, $\mathrm{pH} 7.4,140 \mathrm{mM} \mathrm{NaCl}$ (HEPES-buffered saline, HBS), with $0.1 \%$ bovine serum albumin (BSA), was incubated 2 min at $37^{\circ} \mathrm{C}$, prior to the addition of a fixed concentration of each protease ( $2 \mathrm{nM}$ final concentration). The initial reaction velocities $\left(V_{\mathrm{i}}\right)$, monitored as the changes in absorbance at $405 \mathrm{~nm}$, were plotted against the initial substrate concentration ([S]) and non-linear regression analysis was used to determine the $K_{\mathrm{M}}$ according to equation 1:

$$
V_{i}=\frac{V_{\max } \times[S]}{\left([S]+K_{M}\right)}(\text { Equation } 1)
$$

The $K_{M}$ values for other relevant serine proteases were those reported previously. ${ }^{1}$ The activity of hPK-SPD was evaluated by determining the $K_{M}$ value for hydrolysis of the chromogenic substrate S-2302, which was found to be as $183 \pm 16 \mu \mathrm{M}$ for the first preparations, compared to a $K_{M}$ value of $200 \mu \mathrm{M}$ for the commercial full-length PK. The $K_{\mathrm{M}}$ values of hPK-SPD mutants for hydrolysis of S-2302 were: E217A: $626 \pm$ 148 (3); G99Y: $120 \pm 9$ (3); E217R: $82.1 \pm 12.5$ (3).

Inhibition of the cleavage of high molecular weight kininogen (HMWK) by plasma kallikrein.

Peptides in various concentrations (final concentration: 0-1000 nM) were pre-incubated with hPK $(10 \mathrm{ng})$ at $37^{\circ} \mathrm{C}$ for $15 \mathrm{~min}$. HMWK $(3 \mu \mathrm{g})$ was added in to 
the mixture and subsequently incubated at $37{ }^{\circ} \mathrm{C}$ for $45 \mathrm{~min}$. The cleavage of HMWK was performed in reducing SDS-PAGE (15\% polyacrylamide gels).

Inhibition of the activation of urokinase zymogen (pro-uPA) by plasma kallikrein.

Peptides in various concentrations (final concentration: $0-10,000 \mathrm{nM}$ ) were pre-incubated with PK (final concentration: $1 \mathrm{nM}$ ) at $37{ }^{\circ} \mathrm{C}$ for $15 \mathrm{~min}$. After the addition of pro-uPA (final concentration: $5 \mathrm{nM}$ ), the mixture was incubated at $37^{\circ} \mathrm{C}$ for $45 \mathrm{~min}$. Aprotinin (final concentration: $20 \mu \mathrm{M}$ ) was used to inactivate the PK before the addition of the chromogenic substrate S-2444. The activity of generated uPA was measured by the absorbance at $405 \mathrm{~nm}$. 
Table S1. The binding residues and atoms of mupain-1-16 and huPA H99Y in the crystal structure of the mupain-1-16:huPA-H99Y complex (PDB code: 4X1N) and the corresponding residues and atoms in human plasma kallikrein (hPK).

\begin{tabular}{|c|c|c|}
\hline Mupain-1-16 residue & huPA H99Y & hPK \\
\hline $\mathrm{Ala}^{3} \mathrm{~N}$ & $\mathrm{Thr}^{97} \mathrm{O}$ & No residue \\
\hline $\operatorname{Tyr}^{4} \mathrm{~N}$ & Leu $^{97} \mathrm{O}$ & No residue \\
\hline $\mathrm{Tyr}^{4} \mathrm{OH \eta}$ & $\operatorname{Arg}^{217} \mathrm{NH} \eta 1$ & $\mathrm{Glu}^{217}$ \\
\hline $\operatorname{Ser}^{5} \mathrm{O}$ & Tyr ${ }^{99} \mathrm{OH} \eta$ & $\mathrm{Gly}^{99}$ \\
\hline [L-3-( $N$-amidino-4-piperidyl)alanine $]^{6} \mathrm{~N} 10$ & $\mathrm{Gly}^{218} \mathrm{O}$ & $\mathrm{Gly}^{218}$ \\
\hline [L-3-(N-amidino-4-piperidyl)alanine $]^{6} \mathrm{~N} 10$ & Asp ${ }^{189} \mathrm{O} \delta 2$ & Asp 189 \\
\hline [L-3-( $N$-amidino-4-piperidyl)alanine] $]^{6} \mathrm{~N} 9$ & Asp ${ }^{189} \mathrm{O} \delta 1$ & Asp ${ }^{189}$ \\
\hline [L-3-(N-amidino-4-piperidyl)alanine] ${ }^{6} \mathrm{~N} 9$ & $\operatorname{Ser}^{190} \mathrm{O}$ & Ala ${ }^{190}$ \\
\hline [L-3-(N-amidino-4-piperidyl)alanine] $]^{6} \mathrm{~N} 9$ & $\mathrm{Ser}^{190} \mathrm{O} \gamma$ & $\mathrm{Ala}^{190}$ \\
\hline [L-3-( $N$-amidino-4-piperidyl)alanine $]^{6} \mathrm{O}$ & Gly ${ }^{193} \mathrm{~N}$ & Gly ${ }^{193}$ \\
\hline [L-3-(N-amidino-4-piperidyl)alanine $]^{6} \mathrm{O}$ & $\mathrm{Ser}^{195} \mathrm{O} \gamma$ & $\operatorname{Ser}^{195}$ \\
\hline $\operatorname{Tyr}^{7} \mathrm{O}$ & $\mathrm{Gln}^{192} \mathrm{~N} \varepsilon 2$ & Lys ${ }^{192}$ \\
\hline $\mathrm{Tyr}^{7} \mathrm{OH \eta}$ & $\operatorname{Arg}^{35} \mathrm{NH \eta} 1$ & $\mathrm{Val}^{35}$ \\
\hline $\mathrm{Tyr}^{7} \mathrm{OH \eta}$ & $\operatorname{Arg}^{35} \mathrm{NH \eta} 2$ & $\mathrm{Val}^{35}$ \\
\hline $\mathrm{Tyr}^{7} \mathrm{OH \eta}$ & $\mathrm{Cys}^{58} \mathrm{O}$ & Cys ${ }^{58}$ \\
\hline $\operatorname{Tyr}^{7} \mathrm{O} \alpha$ & $\mathrm{Gln}^{192} \mathrm{~N} \varepsilon 2$ & Lys ${ }^{192}$ \\
\hline $\mathrm{Leu}^{8} \mathrm{O}$ & $\mathrm{Gln}^{192} \mathrm{~N} \varepsilon 2$ & Lys ${ }^{192}$ \\
\hline $\mathrm{Asp}^{9} \mathrm{O} \delta 1$ & $\operatorname{Arg}^{36} \mathrm{NH \eta} 1$ & Lys $^{36}$ \\
\hline $\mathrm{Cys}^{10} \mathrm{O} \alpha$ & $\mathrm{Gln}^{192} \mathrm{~N} \varepsilon 2$ & Lys ${ }^{192}$ \\
\hline
\end{tabular}


Table S2. $K_{i}$ values for inhibition of serine proteases by derivatives of mupain-1. The residues which are different from those in mupain- 1 are underlined. KAc indicates the Lys acetylated at the ultimate amino group.

\begin{tabular}{|c|c|c|c|c|c|c|}
\hline \multirow{2}{*}{ Peptides } & \multirow{2}{*}{ Sequence } & \multicolumn{5}{|c|}{$K_{i}(\mu \mathrm{M})$} \\
\hline & & hPK & mPK & huPA & muPA & huPA H99Y \\
\hline mupain-1 & CPAYSRYLDC & $>650$ & $>680$ & $>1000$ & $0.55 \pm 0.08$ & $15.3 \pm 2.0$ \\
\hline mupain-1-16 & CPAYS $\frac{[\text { L-3- }(N \text {-amidino-4-piperidyl }}{\text { alanine }] \text { YLDC }}$ & $1.58 \pm 0.11$ & $4.61 \pm 0.2(3)$ & $93 \pm 18$ (3) & $0.045 \pm 0.010$ & $2.48 \pm 0.07$ \\
\hline peptide 1 & $\begin{array}{l}\text { CPAYS }[\text { L-3- }(N \text {-amidino-4-piperid } \\
\text { yl)alanine }] \text { ALDC }\end{array}$ & $0.288 \pm 0.046(3)$ & $0.185 \pm 0.004$ & $40.7 \pm 1.6(3)$ & $0.131 \pm 0.018$ & $5.15 \pm 0.78$ \\
\hline peptide 2 & $\begin{array}{c}\text { CPAYS }[\text { L-3- }(N \text {-amidino-4-piperidyl } \\
\stackrel{\text { alanine }] \underline{A L}[\text { KAc }] C}{ }\end{array}$ & $0.119 \pm 0.006$ & $0.130 \pm 0.003$ & $29.8 \pm 2.1$ (3) & $1.25 \pm 0.08$ & $1.15 \pm 0.21$ \\
\hline peptide $\mathbf{3}$ & $\mathrm{CPARS} S \underline{\underline{\mathrm{L}-3-(N \text {-amidino-4-piperidyl }}}$ & $0.118 \pm 0.021$ & $0.086 \pm 0.023$ & $>1000$ & $182 \pm 13(3)$ & $>1000$ \\
\hline peptide 4 & $\begin{array}{c}\mathrm{CPA} \\
\underline{\mathrm{KS}}[\underline{\mathrm{L}-3-(N \text {-amidino-4-piperidyl }} \\
\underline{\text { alanine }]}] \underline{\mathrm{AL}}[\underline{\mathrm{KAc}}] \mathrm{C}\end{array}$ & $0.164 \pm 0.008$ & $0.362 \pm 0.021$ (3) & $>1000$ & $>1000$ & $>1000$ \\
\hline peptide 5 & $\begin{array}{c}\mathrm{CPARA}[\underline{\mathrm{L}-3-(N \text {-amidino-4-piperidy }} \\
\text { l)alanine }] \underline{\mathrm{AL}}[\mathrm{KAc}] \mathrm{C}\end{array}$ & $1.25 \pm 0.30$ & $0.871 \pm 0.145$ & $>1000$ & $>1000$ & $>1000$ \\
\hline peptide 6 & $\mathrm{CPARF}[\underline{\mathrm{L}-3-(N \text {-amidino-4-piperidyl }}$ & $0.064 \pm 0.007$ (3) & $0.101 \pm 0.003$ & $>1000$ & $>1000$ & $>1000$ \\
\hline peptide 7 & CPARL $[\underline{\mathrm{L}-3-(N \text {-amidino-4-piperidyl }}$ & $1.20 \pm 0.101$ & $0.755 \pm 0.046$ & $>1000$ & $>1000$ & $>1000$ \\
\hline peptide 8 & CPARF $\frac{L \text { L-3- }(N \text {-amidino-4-piperidyl }}{\text { alanine }] \text { ALFC }}$ & $0.008 \pm 0.001(3)$ & $0.026 \pm 0.002$ & $>1000$ & $>1000$ & $>1000$ \\
\hline peptide 9 & $\mathrm{CPKRF}\left[\frac{\mathrm{L}-3-(N \text {-amidino-4-piperidyl }}{\text { alanine }] \underline{A L F C}}\right.$ & $0.022 \pm 0.006(3)$ & $0.043 \pm 0.001$ & $>1000$ & $>1000$ & $>1000$ \\
\hline peptide $\mathbf{1 0}$ & CPARF$\left[\frac{\mathrm{L}-3 \text { - }(N \text {-amidino-4-piperidyl }}{\text { alanine }] \text { ALWC }}\right.$ & $0.014 \pm 0.003$ & $0.050 \pm 0.005$ & $>1000$ & $>1000$ & $>1000$ \\
\hline
\end{tabular}


Figure S1. SDS-PAGE analysis of recombinant catalytic domain of human plasma kallikrein (hPK-SPD). The theoretical molecular weight of hPK-SPD is $28 \mathrm{kDa}$. In SDS-PAGE, the recombinant protein migrates as $\mathrm{M}_{\mathrm{r}} 35,000$ because of the glycosylation.

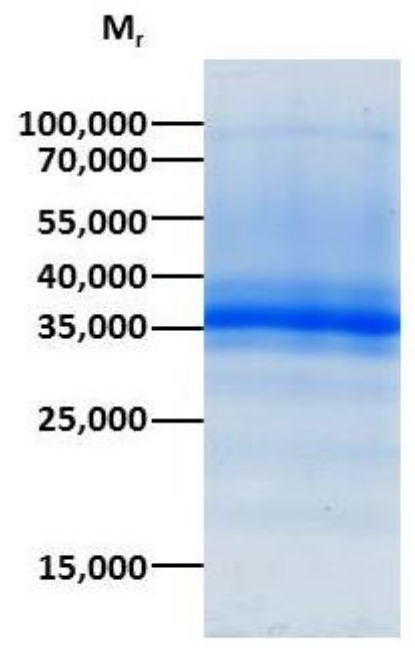


Figure S2. The effects of the PK inhibitors on the activity of PK towards proteinaceous substrates. (a-c) Inhibition of the cleavage of HMWK, by peptide 8 (a), peptide 9 (b), or peptide $10(\mathbf{c})$. FL: the un-cleaved full-length HMWK $\left(\mathrm{M}_{\mathrm{r}}\right.$ 120,000); HC: the heavy-chain fragment of cleaved HMWK $\left(\mathrm{M}_{\mathrm{r}} 70,000\right)$; LC: the light-chain fragment of cleaved HMWK $\left(\mathrm{M}_{\mathrm{r}}\right.$ 50,000). (d) Inhibition of activation of pro-uPA activation. $\mathrm{V}_{\mathrm{i}}$ and $\mathrm{V}_{0}$ indicate the rates of S-2444 hydrolysis in the presence and absence of peptides. The $\mathrm{IC}_{50}$ values, as calculated by the regression fitting, were $11.3 \mathrm{nM}, 42.6 \mathrm{nM}$, and $29.4 \mathrm{nM}$, for peptides $\mathbf{8}, 9$ and $\mathbf{1 0}$, respectively. The concentrations of the peptides needed to inhibit HMWK cleavage in this experiment are much higher than the $K_{i}$ values in Tables 1 and S2, due to an uncorrected competition with the inhibitor from the relatively high HMWK concentrations.

a

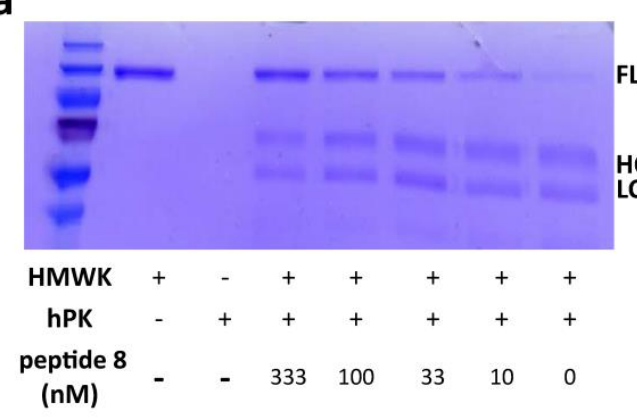

C

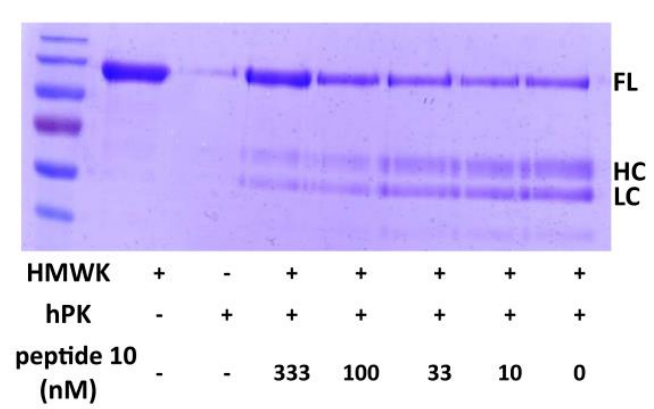

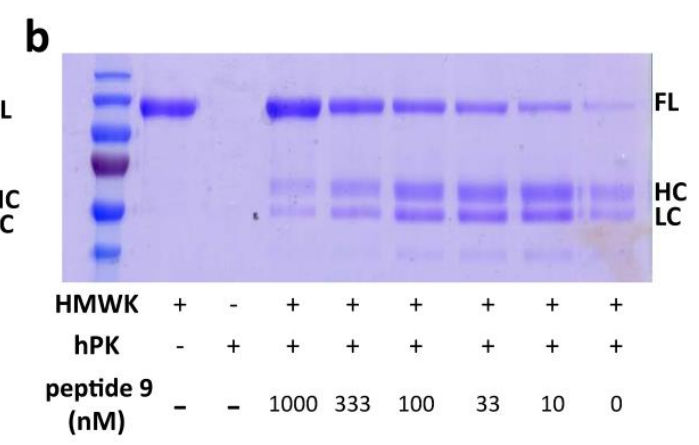

d

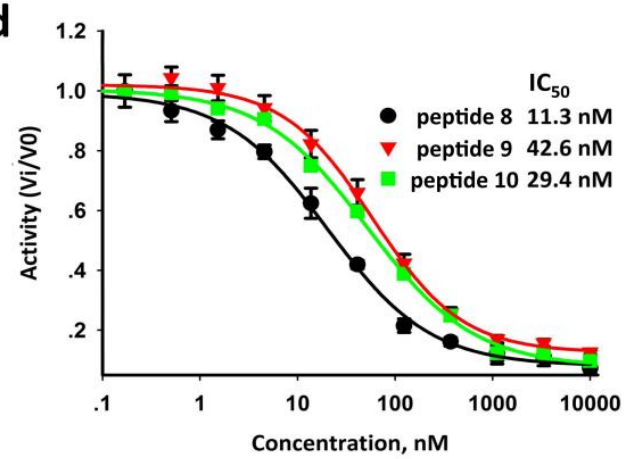


Figure S3. SPR analysis of the binding of peptides to proteases. Full length hPK was immobilized on a CM5 to about $500 \mathrm{RU}$. The indicated peptides were then injected over the chip for $90 \mathrm{~s}$ at $25^{\circ} \mathrm{C}$ in a two-fold dilution series, followed by dissociation for $110 \mathrm{~s}$. The flow rate was $30 \mu \mathrm{l} / \mathrm{min}$. The fitted curves correspond to $k_{\mathrm{on}}=31.36 \times 10^{5} \mathrm{M}^{-1} \mathrm{~s}^{-1}, k_{\mathrm{off}}$ $=1.69 \times 10^{-2} \mathrm{~s}^{-1}, K_{\mathrm{D}}=4.50 \mathrm{nM}$ (peptide 8); $k_{\text {on }}=30.0 \times 10^{5} \mathrm{M}^{-1} \mathrm{~s}^{-1}, k_{\text {off }}=2.24 \times 10^{-2} \mathrm{~s}^{-1}$, $K_{\mathrm{D}}=7.47 \mathrm{nM}$ (peptide 9); $k_{\mathrm{on}}=115 \times 10^{5} \mathrm{M}^{-1} \mathrm{~s}^{-1}, k_{\text {off }}=2.55 \times 10^{-2} \mathrm{~s}^{-1}, K_{D}=3.40 \mathrm{nM}$ (peptide 10).
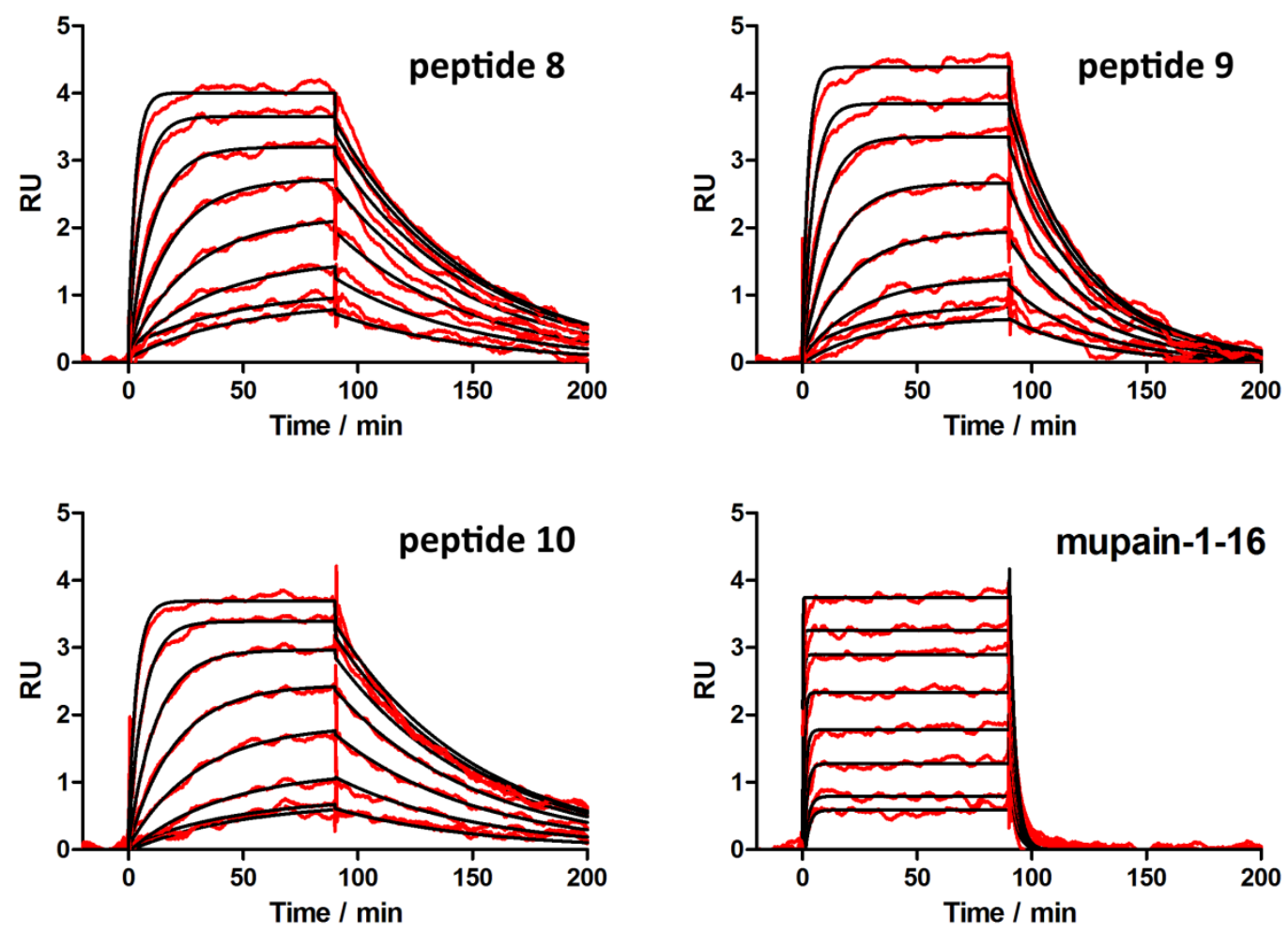
Figure S4. Stability of peptide 8 and peptide 10 in human plasma. Peptides (40 $\mu \mathrm{M})$ were incubated with $40 \%$ human plasma at $37^{\circ} \mathrm{C}$ for the indicated time periods. The activity of peptides was determined at a concentration of plasma of $2 \%$, determining the $\mathrm{IC}_{50}$ values for inhibition of plasma kallikrein $(\mathrm{PK})$ by the peptide in various concentrations by a chromogenic assay. Normalized activity in $\%=\mathrm{IC}_{50}(\mathrm{t}=0 \mathrm{~h}) / \mathrm{IC}_{50}$ (different time point) $\cdot 100$

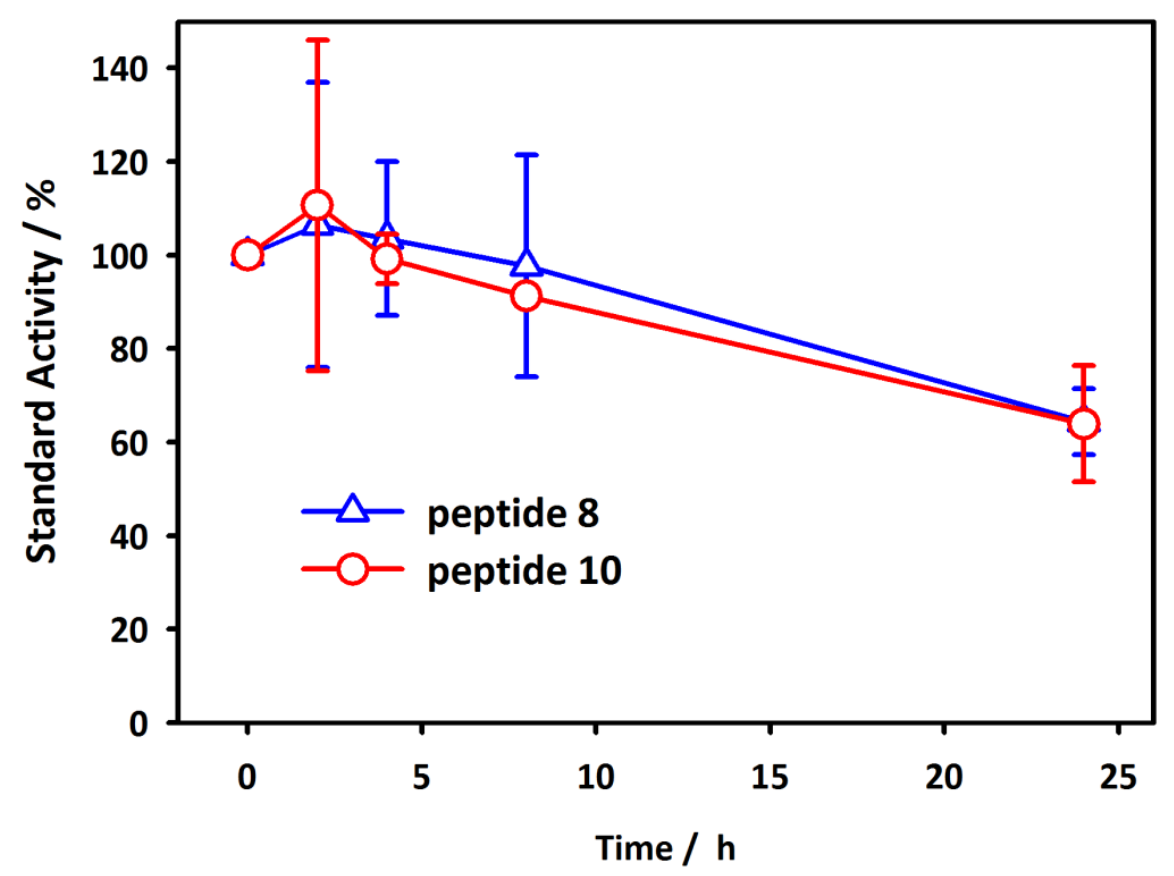


Table S3. X-ray data collection and model refinement statistics

\begin{tabular}{|c|c|c|c|}
\hline $\begin{array}{c}\text { Crystals } \\
\text { PDB code }\end{array}$ & $\begin{array}{c}\text { hPK-peptide } 8 \\
4 Z J 4 \\
\end{array}$ & $\begin{array}{c}\text { hPK-peptide } 9 \\
\text { 4ZJ5 } \\
\end{array}$ & $\begin{array}{c}\text { hPK-peptide } 10 \\
\text { 4ZJ6 } \\
\end{array}$ \\
\hline Beamline & SER-CAT 22-ID (APS) & BL17U (SSRF) & BL17U (SSRF) \\
\hline X-ray wavelength $(\AA)$ & 1.0 & 1.0 & 1.0 \\
\hline Resolution limits (̊̊) & 1.50 & 1.74 & 1.55 \\
\hline Space group & $\mathrm{P}_{5}$ & $\mathrm{P} 6_{5}$ & $\mathrm{P}_{5}$ \\
\hline Cell parameters (̊̊) & $a=90.28, b=90.28, c=57.62$ & $a=90.15, b=90.15, c=57.26$ & $a=90.34, b=90.34, c=57.35$ \\
\hline $\begin{array}{l}\text { Temperature of } \\
\text { experiments }(K)\end{array}$ & 100 & 100 & 100 \\
\hline Completeness (\%) & 99.4 & 99.9 & 100 \\
\hline Redundancy & $5.7(2.6)^{\mathrm{a}}$ & $5.5(4.2)^{\mathrm{a}}$ & $5.5(4.3)^{\mathrm{a}}$ \\
\hline Average I/ $\sigma$ & $14.2(2.2)^{\mathrm{a}}$ & $15.2(2.0)^{\mathrm{a}}$ & $26.1(2.9)^{\mathrm{a}}$ \\
\hline $\mathbf{R}_{\text {merge }}{ }^{b}$ & $0.110(0.575)^{\mathrm{a}}$ & $0.073(0.813)^{\mathrm{a}}$ & $0.057(0.592)^{\mathrm{a}}$ \\
\hline Refinement data & hPK-peptide 8 & hPK-peptide 9 & hPK-peptide 10 \\
\hline R-factor & 0.237 & 0.231 & 0.221 \\
\hline R-free & 0.258 & 0.244 & 0.243 \\
\hline $\begin{array}{c}\text { Average B-factor }\left(\AA^{2}\right) \text { of } \\
\text { protein }\end{array}$ & 18.4 & 29.4 & 21.2 \\
\hline 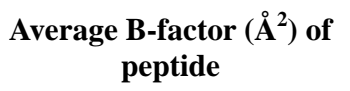 & 21.8 & 36.9 & 23.5 \\
\hline $\begin{array}{l}\text { r.m.s deviation of bond } \\
\text { lengths }(\AA)\end{array}$ & 0.008 & 0.007 & 0.008 \\
\hline $\begin{array}{l}\text { r.m.s deviation of angle } \\
\text { lengths }\left({ }^{\circ}\right)\end{array}$ & 1.310 & 1.360 & 1.420 \\
\hline $\begin{array}{c}\text { Ramachandran analysis } \\
(\%)\end{array}$ & $97.1^{\mathrm{c}}, 2.1^{\mathrm{d}}, 0.8^{\mathrm{e}}$ & $97.1^{\mathrm{c}}, 2.1^{\mathrm{d}}, 0.8^{\mathrm{e}}$ & $97.1^{\mathrm{c}}, 2.1^{\mathrm{d}}, 0.8^{\mathrm{e}}$ \\
\hline
\end{tabular}

\footnotetext{
${ }^{\mathrm{a}}$ Numbers in parentheses refer to the highest resolution shells.

${ }^{\mathrm{b}} \mathrm{Rmerge}=\Sigma\left|\mathrm{I}_{\mathrm{i}^{-}}<\mathrm{I}>\right| / \Sigma \mathrm{I}_{\mathrm{i}}$, where Ii is the intensity of the ith observation and $\langle\mathrm{I}\rangle$ is the mean intensity of the reflections.

${ }^{c}$ Percentage of residues in most favored regions.

${ }^{\mathrm{d}}$ Percentage of residues in additional allowed regions.

${ }^{\mathrm{e}}$ Percentage of residues in generously allowed regions.
} 
Table S4. Potential polar interactions and distances between peptide $\mathbf{8}$ residues and hPK residues in the crystal structure of hpk-peptide $\mathbf{8}$ complex (PDB code: 4ZJ4).

\begin{tabular}{|c|c|c|}
\hline peptide 8 residue & hPK residue & Distance, $\AA$ \\
\hline $\mathrm{Cys}^{1} \mathrm{~N}$ & $\mathrm{Asp}^{60} \mathrm{O} 2$ & 2.81 \\
\hline $\operatorname{Arg}^{4} \mathrm{~N} 1$ & $\operatorname{Tyr}^{174} \mathrm{O} 2$ & 3.68 \\
\hline $\mathrm{Arg}^{4} \mathrm{~N} 2$ & $\mathrm{Ser}^{97} \mathrm{O}$ & 3.19 \\
\hline $\operatorname{Arg}^{4} \mathrm{~N} 2$ & $\mathrm{Glu}^{98} \mathrm{O}$ & 2.92 \\
\hline $\mathrm{Arg}^{4} \mathrm{O}$ & $\mathrm{Gly}^{216} \mathrm{O}$ & 3.10 \\
\hline $\mathrm{Arg}^{4} \mathrm{O}$ & $\mathrm{Gly}^{216} \mathrm{~N}$ & 2.97 \\
\hline $\mathrm{Phe}^{5} \mathrm{O}$ & Lys ${ }^{192} \mathrm{~N} 2$ & 3.13 \\
\hline $\begin{array}{c}{\text { [L-3-(N-amidino-4-piperidyl }) \text { alanine }]^{6}}_{\text {N14 }}\end{array}$ & $\mathrm{Gly}^{219} \mathrm{O}$ & 3.01 \\
\hline 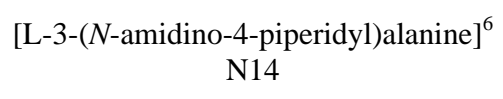 & $\mathrm{Asp}^{189} \mathrm{O} \delta 2$ & 2.93 \\
\hline $\begin{array}{c}{\text { [L-3-(N-amidino-4-piperidyl)alanine }]^{6}}_{\text {N14 }} \\
\text { ( }\end{array}$ & $\operatorname{Ser}^{190} \mathrm{O}$ & 3.30 \\
\hline $\begin{array}{c}\text { [L-3-(N-amidino-4-piperidyl)alanine }]^{6} \\
\text { N13 }\end{array}$ & $\mathrm{Asp}^{189} \mathrm{O} \delta 1$ & 3.01 \\
\hline $\begin{array}{c}{[\text { L-3-(N-amidino-4-piperidyl)alanine }]^{6}} \\
\text { N13 }\end{array}$ & $\operatorname{Ser}^{190} \mathrm{O}$ & 3.46 \\
\hline $\begin{array}{c}{[\text { L-3-(N-amidino-4-piperidyl)alanine }]^{6}} \\
\mathrm{O}\end{array}$ & Gly $^{193} \mathrm{~N}$ & 3.10 \\
\hline
\end{tabular}


Table S5. Potential polar interactions and distances between peptide 9 residues and hPK residues in the crystal structure of hpk-peptide 9 complex (PDB code: 4ZJ5).

\begin{tabular}{|c|c|c|}
\hline peptide 9 residue & hPK residue & Distance, $\AA$ \\
\hline Cys $^{1} \mathrm{~N}$ & $\operatorname{Asp}^{60} \mathrm{O} 2$ & 2.86 \\
\hline Lys3 O & Lys ${ }^{192} \mathrm{~N} 2$ & 3.46 \\
\hline $\operatorname{Arg}^{4} \mathrm{~N} 1$ & $\mathrm{Tyr}^{174} \mathrm{O} 2$ & 3.68 \\
\hline $\operatorname{Arg}^{4} \mathrm{~N} 2$ & $\mathrm{Ser}^{97} \mathrm{O}$ & 3.24 \\
\hline $\operatorname{Arg}^{4} \mathrm{~N} 2$ & $\mathrm{Glu}^{98} \mathrm{O}$ & 2.83 \\
\hline $\mathrm{Arg}^{4} \mathrm{O}$ & $\mathrm{Gly}^{216} \mathrm{O}$ & 3.14 \\
\hline $\mathrm{Arg}^{4} \mathrm{O}$ & $\mathrm{Gly}^{216} \mathrm{~N}$ & 3.03 \\
\hline $\mathrm{Phe}^{5} \mathrm{O}$ & Lys ${ }^{192} \mathrm{~N} 2$ & 3.05 \\
\hline $\begin{array}{c}{\text { [L-3-(N-amidino-4-piperidyl)alanine }]^{6}}_{\text {N14 }}\end{array}$ & $\mathrm{Gly}^{219} \mathrm{O}$ & 3.02 \\
\hline $\begin{array}{c}{\text { [L-3-( } N \text {-amidino-4-piperidyl)alanine }]^{6}}_{\text {N14 }}\end{array}$ & $\operatorname{Asp}^{189} \mathrm{O} \delta 2$ & 2.86 \\
\hline $\begin{array}{c}{\text { [L-3-(N-amidino-4-piperidyl)alanine }]^{6}}_{\text {N14 }} \\
\text { ( }\end{array}$ & $\operatorname{Ser}^{190} \mathrm{O}$ & 3.33 \\
\hline $\begin{array}{c}{[\text { L-3-(N-amidino-4-piperidyl)alanine }]^{6}} \\
\text { N13 }\end{array}$ & $\mathrm{Asp}^{189} \mathrm{O} \delta 2$ & 3.47 \\
\hline $\begin{array}{c}{\text { [L-3-(N-amidino-4-piperidyl)alanine }]^{6}}_{\text {N13 }}\end{array}$ & $\operatorname{Asp}^{189} \mathrm{O} \delta 1$ & 2.97 \\
\hline $\begin{array}{c}{\text { [L-3-( } N \text {-amidino-4-piperidyl)alanine }{ }^{6}}_{\mathrm{O}}\end{array}$ & Gly ${ }^{193} \mathrm{~N}$ & 3.18 \\
\hline $\begin{array}{c}{\text { [L-3-( } N \text {-amidino-4-piperidyl)alanine }]^{6}}_{\mathrm{O}}\end{array}$ & $\operatorname{Ser}^{195} \mathrm{O}$ & 3.25 \\
\hline
\end{tabular}


Table S6 Potential polar interactions and distances between peptide $\mathbf{1 0}$ residues and hPK residues in the crystal structure of hpk-peptide $\mathbf{1 0}$ complex (PDB code: 4ZJ6)

\begin{tabular}{|c|c|c|}
\hline peptide 10 residue & hPK residue & Distance, $\AA$ \\
\hline Cys $^{1} \mathrm{~N}$ & $\mathrm{Asp}^{60} \mathrm{O} 2$ & 2.73 \\
\hline Ala3 O & Lys ${ }^{192} \mathrm{~N} 2$ & 3.15 \\
\hline $\operatorname{Arg}^{4} \mathrm{~N} 1$ & $\mathrm{Tyr}^{174} \mathrm{O} 2$ & 3.68 \\
\hline $\operatorname{Arg}^{4} \mathrm{~N} 2$ & $\mathrm{Ser}^{97} \mathrm{O}$ & 3.35 \\
\hline $\operatorname{Arg}^{4} \mathrm{~N} 2$ & $\mathrm{Glu}^{987} \mathrm{O}$ & 2.96 \\
\hline $\mathrm{Arg}^{4} \mathrm{O}$ & $\mathrm{Gly}^{216} \mathrm{O}$ & 2.99 \\
\hline $\operatorname{Arg}^{4} \mathrm{O}$ & $\mathrm{Gly}^{216} \mathrm{~N}$ & 2.96 \\
\hline $\mathrm{Phe}^{5} \mathrm{O}$ & Lys ${ }^{192} \mathrm{~N} 2$ & 3.05 \\
\hline [L-3-( $N$-amidino-4-piperidyl)alanine] ${ }^{6} \mathrm{~N} 14$ & $\mathrm{Gly}^{219} \mathrm{O}$ & 3.05 \\
\hline [L-3-(N-amidino-4-piperidyl)alanine] ${ }^{6} \mathrm{~N} 14$ & $\mathrm{Asp}^{189} \mathrm{O} \delta 2$ & 2.91 \\
\hline [L-3-(N-amidino-4-piperidyl)alanine] ${ }^{6} \mathrm{~N} 14$ & $\operatorname{Ser}^{190} \mathrm{O}$ & 3.28 \\
\hline [L-3-( $N$-amidino-4-piperidyl)alanine] ${ }^{6} \mathrm{~N} 13$ & $\operatorname{Asp}^{189} \mathrm{O} \delta 1$ & 3.06 \\
\hline [L-3-( $N$-amidino-4-piperidyl)alanine $]^{6} \mathrm{O}$ & $\mathrm{Gly}^{193} \mathrm{~N}$ & 3.13 \\
\hline [L-3-( $N$-amidino-4-piperidyl)alanine $]^{6} \mathrm{O}$ & $\mathrm{Ser}^{195} \mathrm{O}$ & 3.42 \\
\hline
\end{tabular}


Figure S5. The interaction surface formed by residues 4-9 (yellow) is much larger than the interaction surface formed by residues 1-3 and 10 (blue) in the crystal structures of mupain-1-16 in complex with huPA H99Y (a) and peptide $\mathbf{1 0}$ in complex with hPK (b). The residues of the proteases that interact with both residues 4-9 and residues 10-3 are colored green.
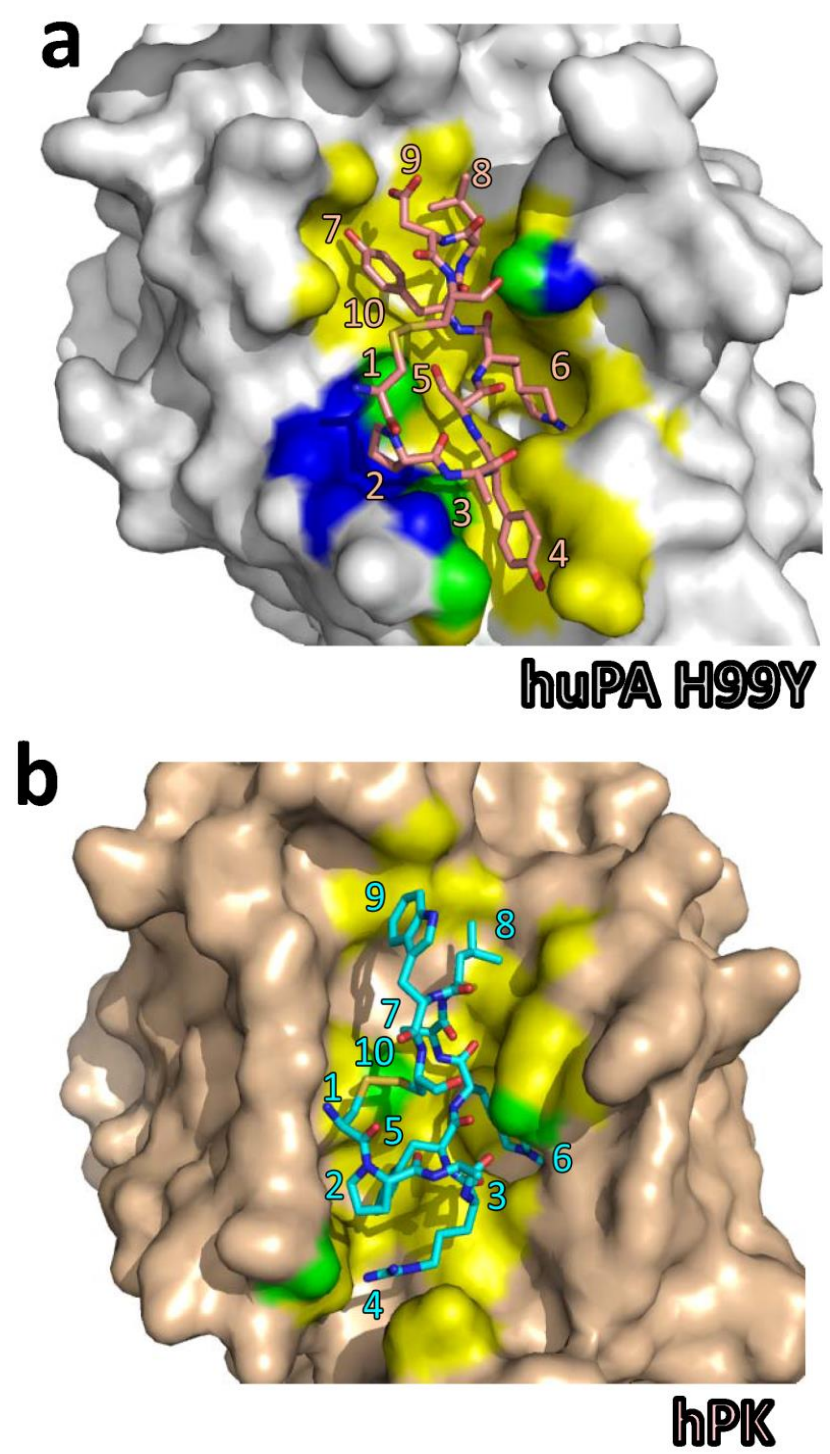
Figure S6. Enzyme-binding residues of mupain-1-16 (a) and peptide 10 (b) docked onto the surface of the relevant enzymes.
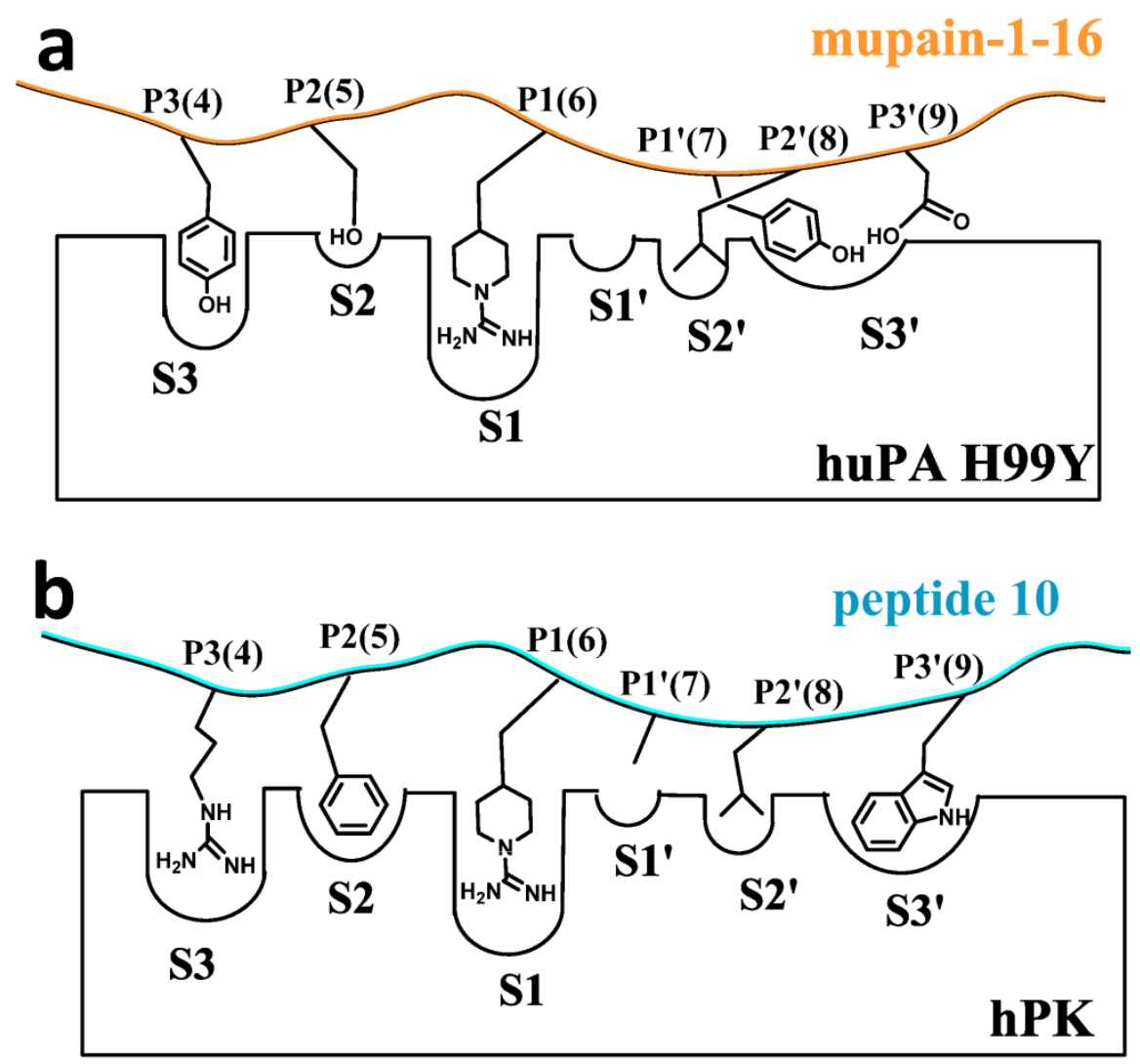
Figure S7. HPLC chromatograms and mass spectra of all peptides.

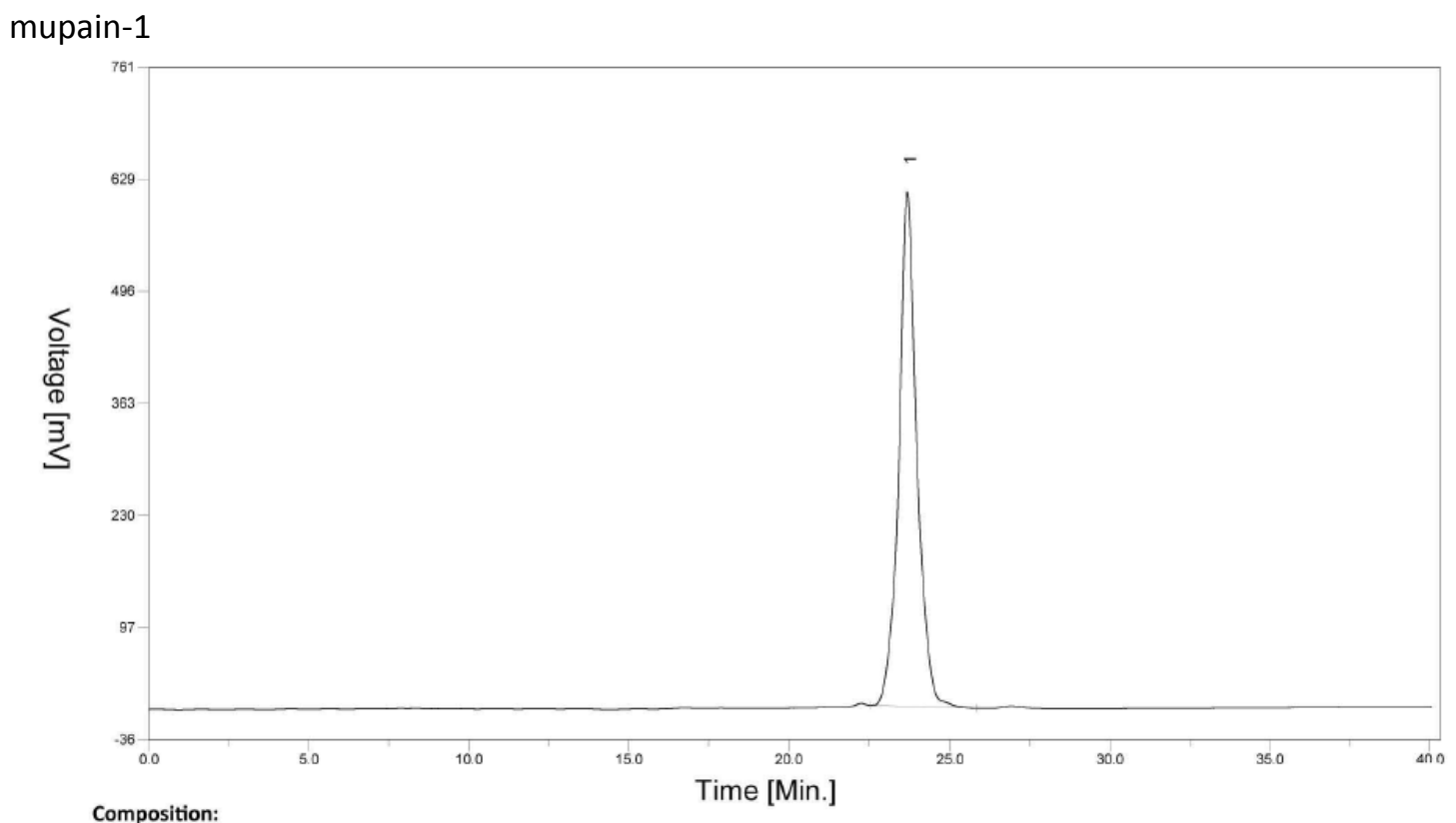

\begin{tabular}{|clllllll|}
\hline$\#$ & Component & RT $(\mathrm{min})$ & Height $(\mathrm{mV})$ & Area $\left(\mathrm{mV}^{*} \mathrm{sec}\right)$ & Area $\%$ & Concentration & Concentration \% \\
\hline 1 & Unknown & 23.66 & 609.84 & 23953.50 & 100.0000 & 0.0000 & 0.0000 \\
\hline Total: & & & 609.84 & 23953.50 & 100 & & \\
\hline
\end{tabular}

D:DatalHMDlmupain-1
mupain-1 \#67 RT: $2.39 \quad$ AV: 1 NL: $1.05 \mathrm{E} 9$

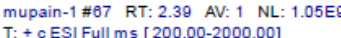

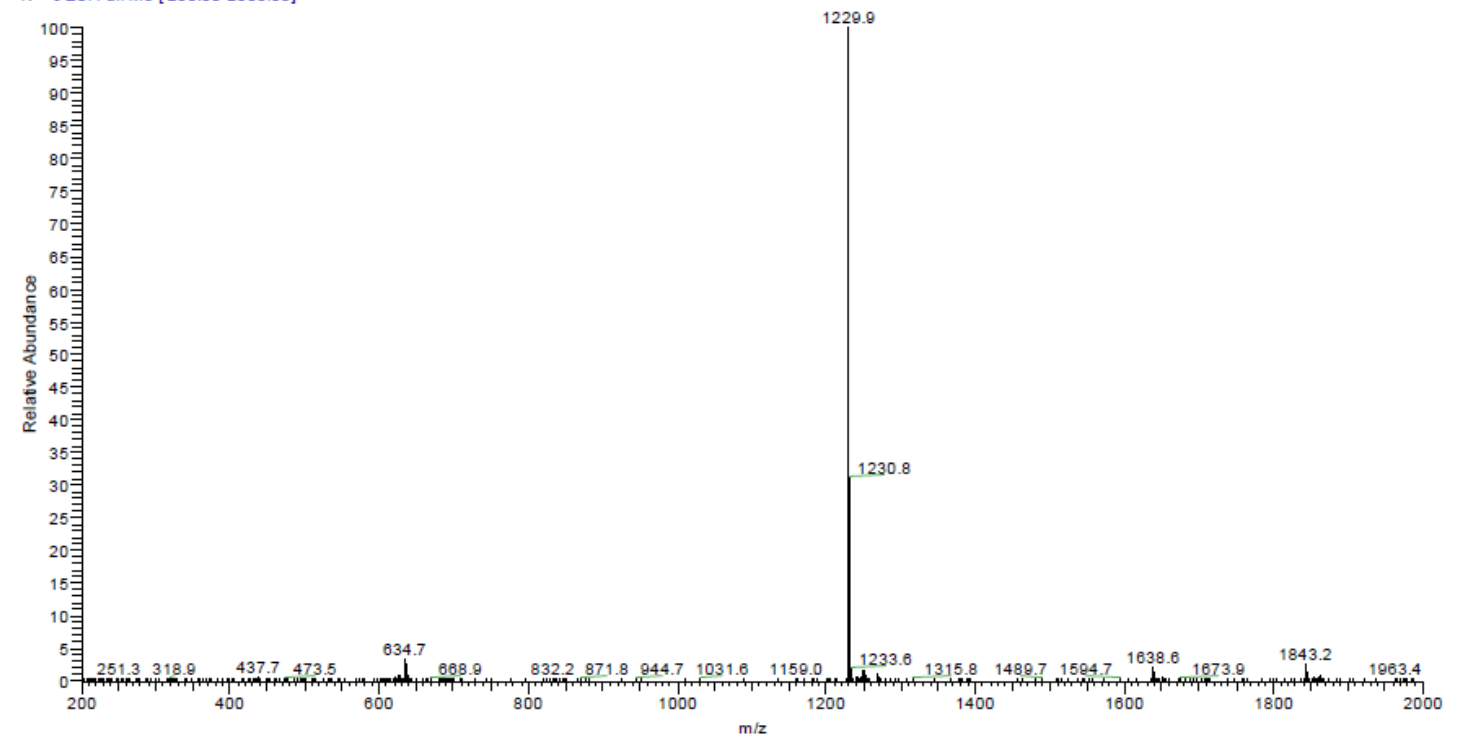


mupain-1-16

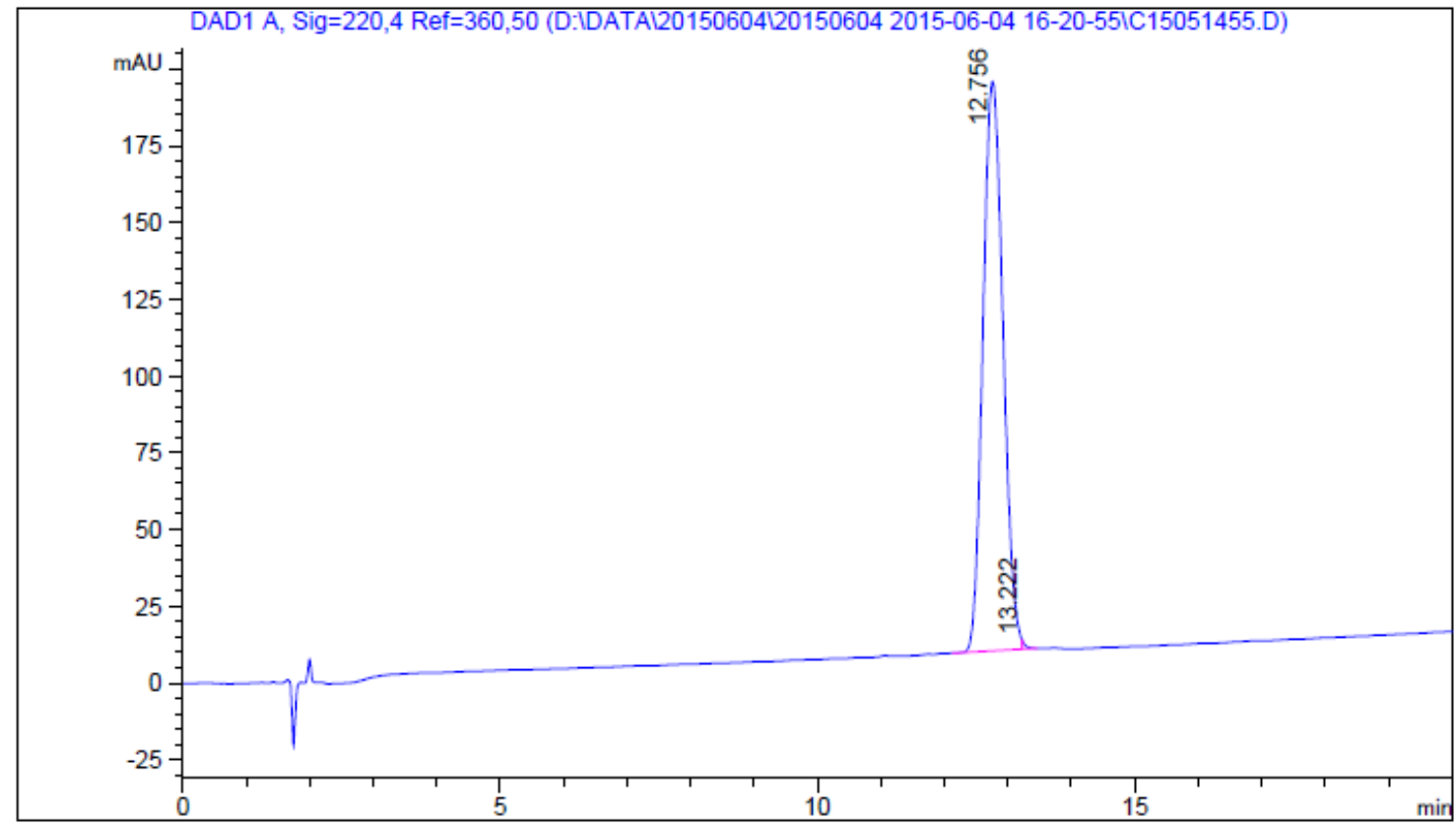

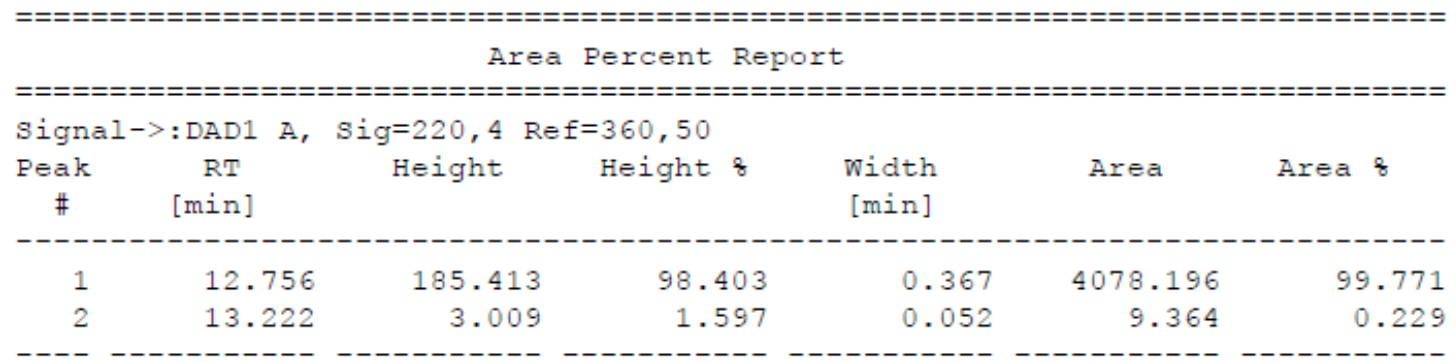

\section{User Spectra}

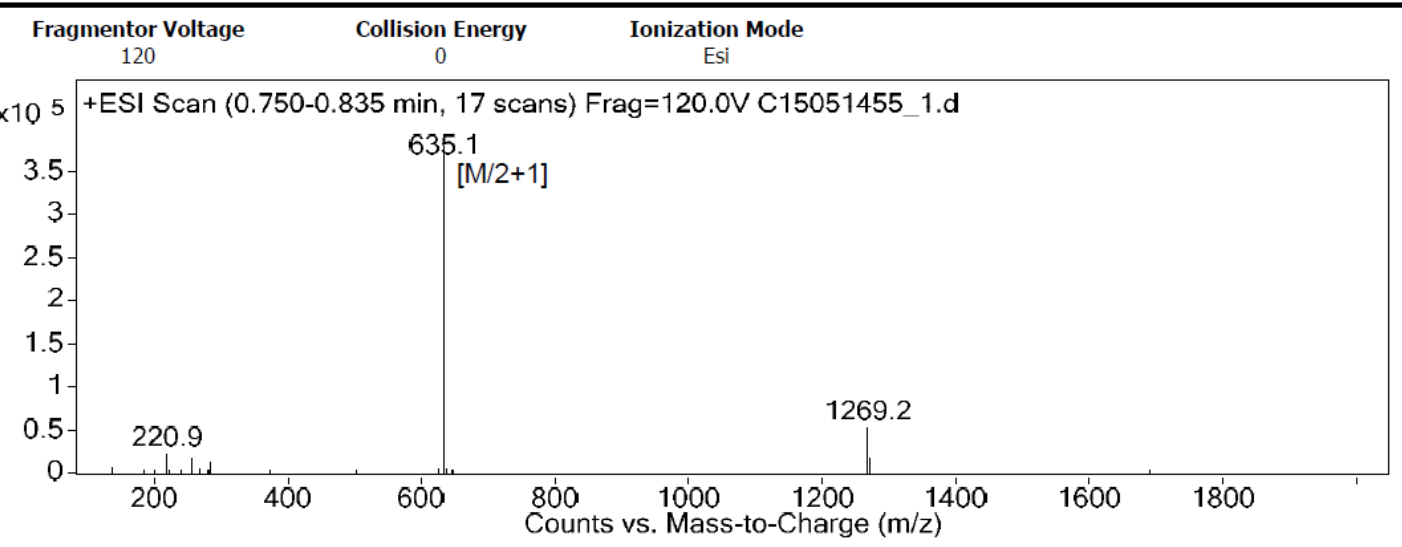




\section{Peptide 1}

$S \mathrm{M} \perp \mathrm{N} \cdot \mathrm{M}$

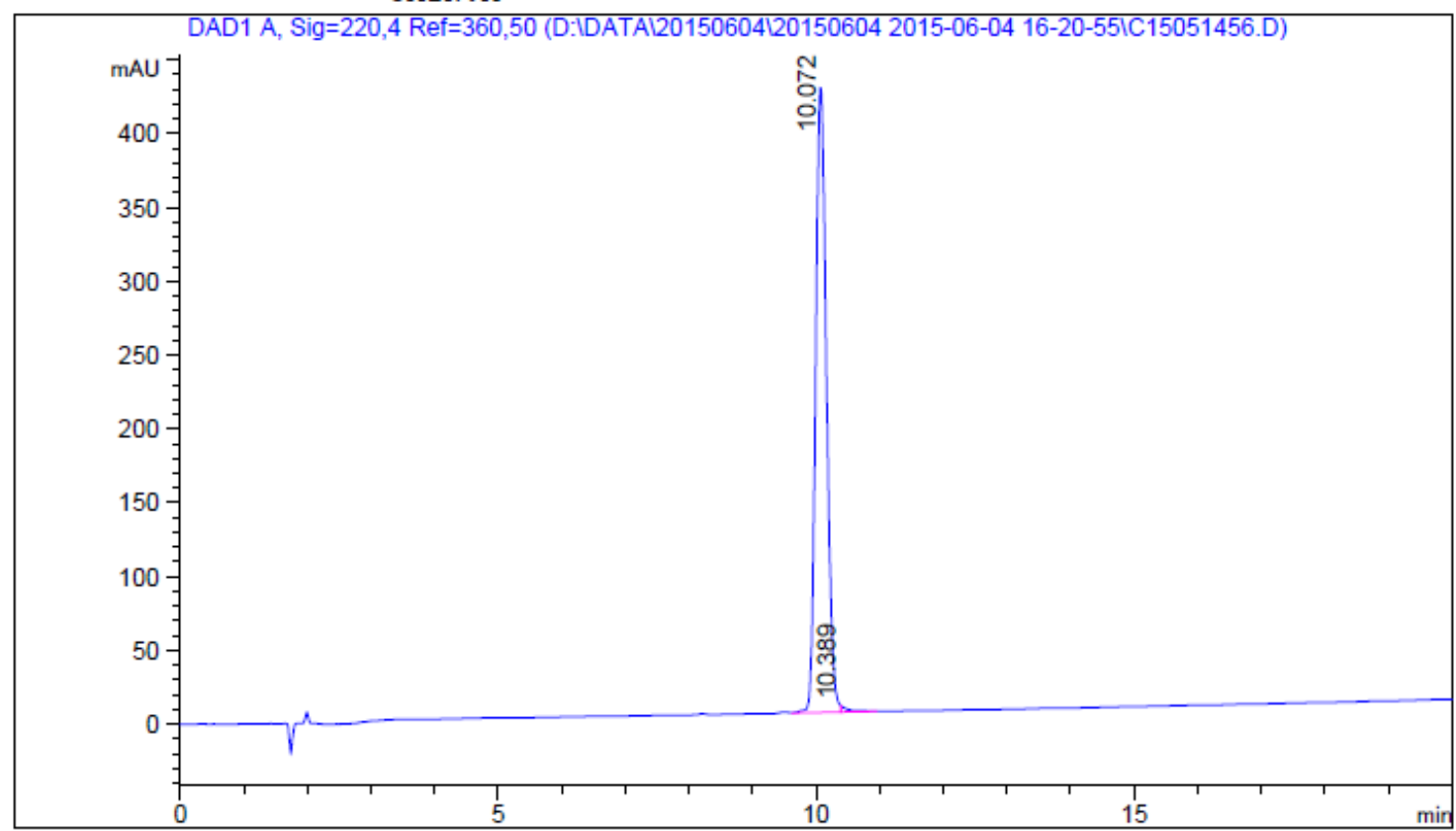

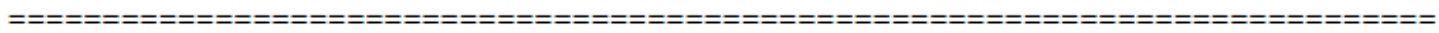
Area Percent Report

\begin{tabular}{|c|c|c|c|c|c|c|}
\hline--1 & --1 & & ---- & --------0 & ------1 & -------- \\
\hline 1 & 10.072 & 423.284 & 99.020 & 0.196 & 4984.083 & 99.376 \\
\hline 2 & 10.389 & 4.190 & 0.980 & 0.125 & 31.313 & 0.624 \\
\hline
\end{tabular}

\section{User Spectra}

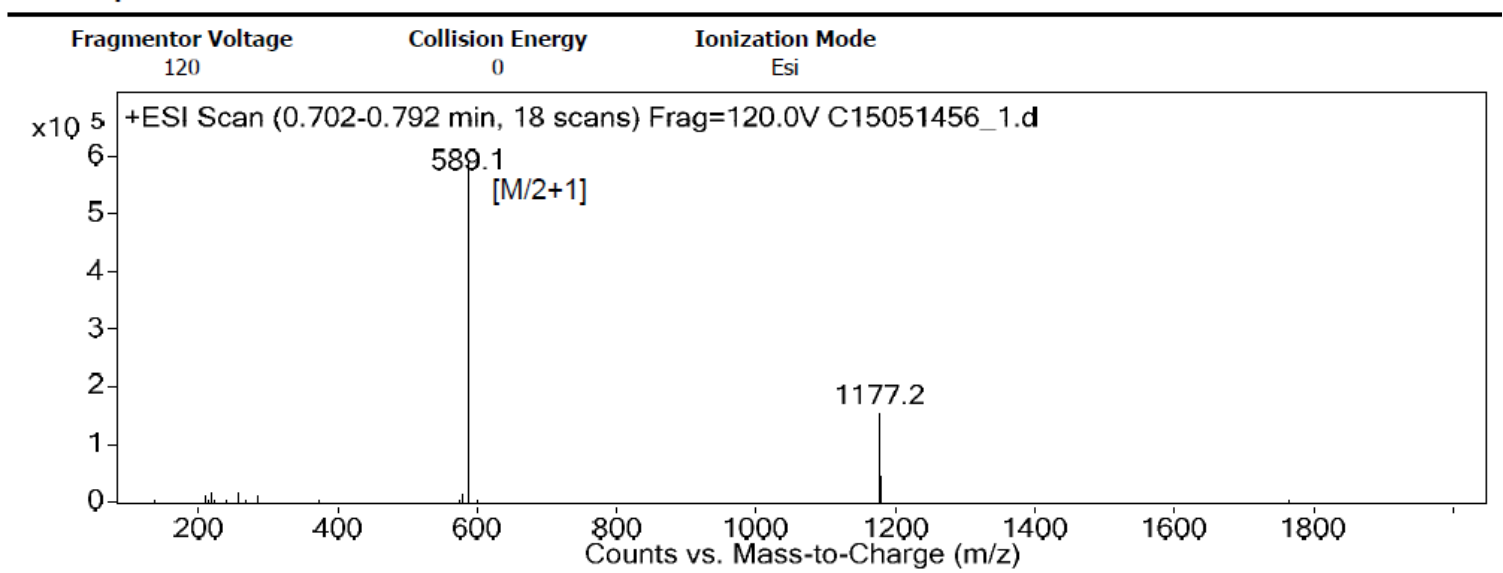




\section{Peptide 2}

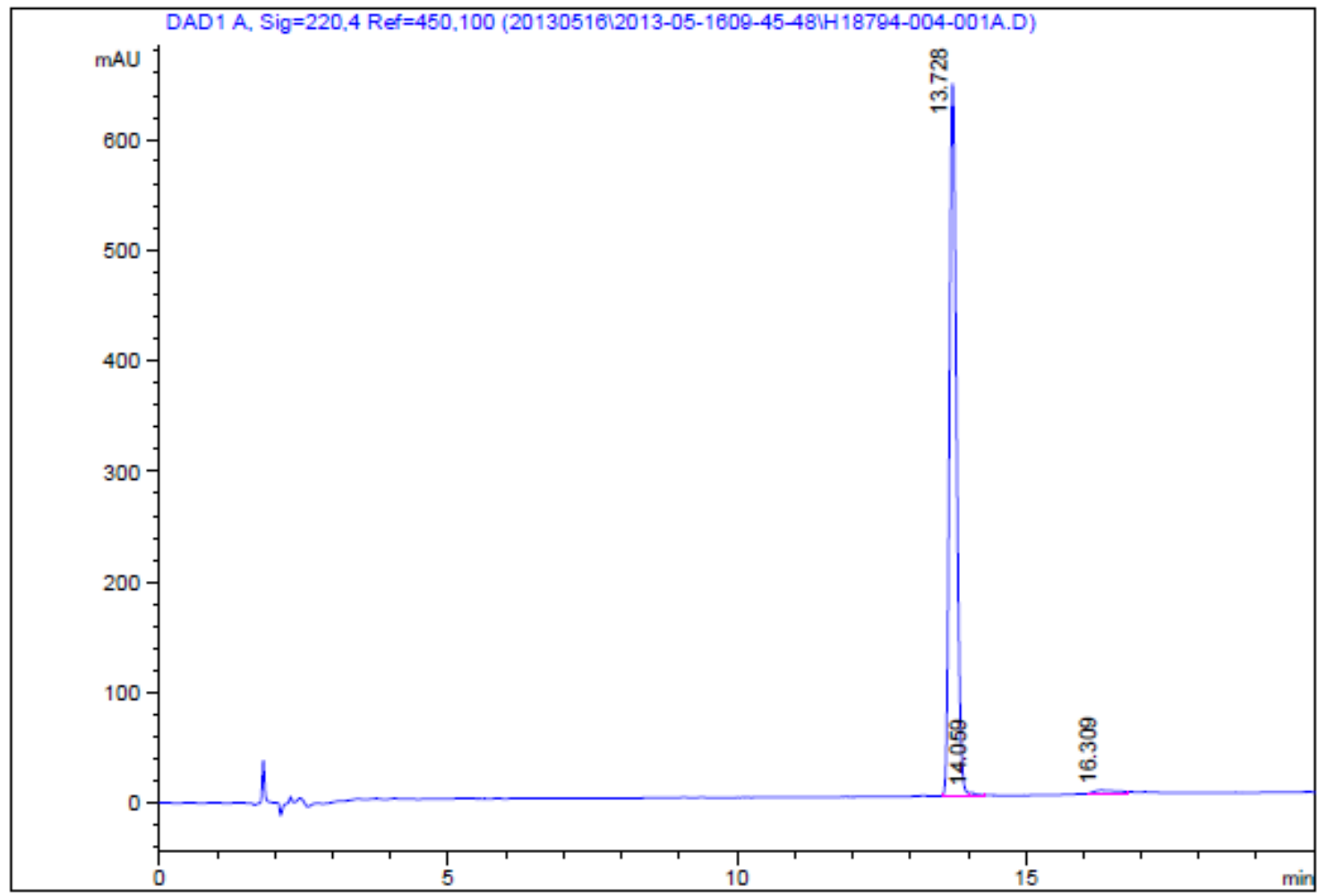

Area Percent Report

\begin{tabular}{|c|c|c|c|c|c|c|}
\hline Signe & \multirow{2}{*}{$\begin{array}{l}: \mathrm{DAD} 1 \mathrm{~A}, \\
\mathrm{RT}\end{array}$} & \multicolumn{2}{|c|}{ Sig $=220,4$ Ref $=450,100$} & \multirow{2}{*}{$\begin{array}{l}\text { Width } \\
\text { [min] }\end{array}$} & \multirow[b]{2}{*}{ Area } & \multirow[b]{2}{*}{ Area 웅 } \\
\hline Peak & & Height & Height 8 & & & \\
\hline & & & & & & \\
\hline 1 & 13.728 & 644.302 & 99.083 & 0.141 & 5437.457 & 97.675 \\
\hline 3 & 16.309 & 3.346 & 0.515 & 0.526 & 105.649 & 1.897 \\
\hline
\end{tabular}

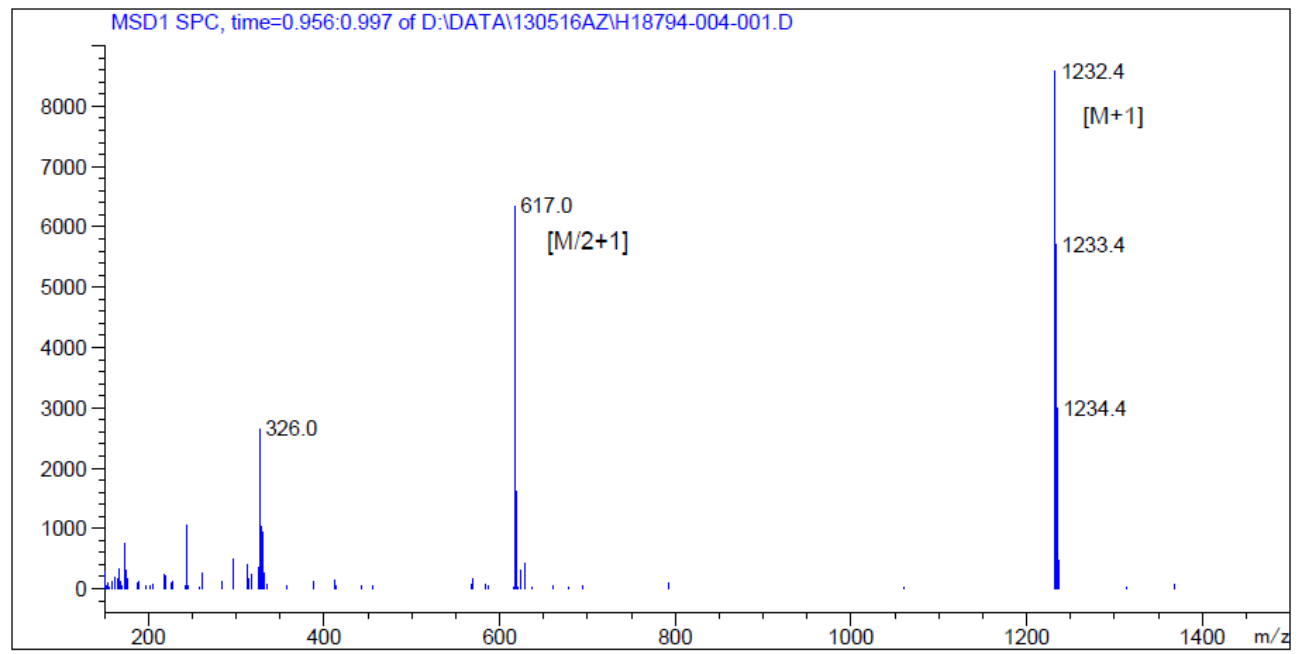

Peptide 3 


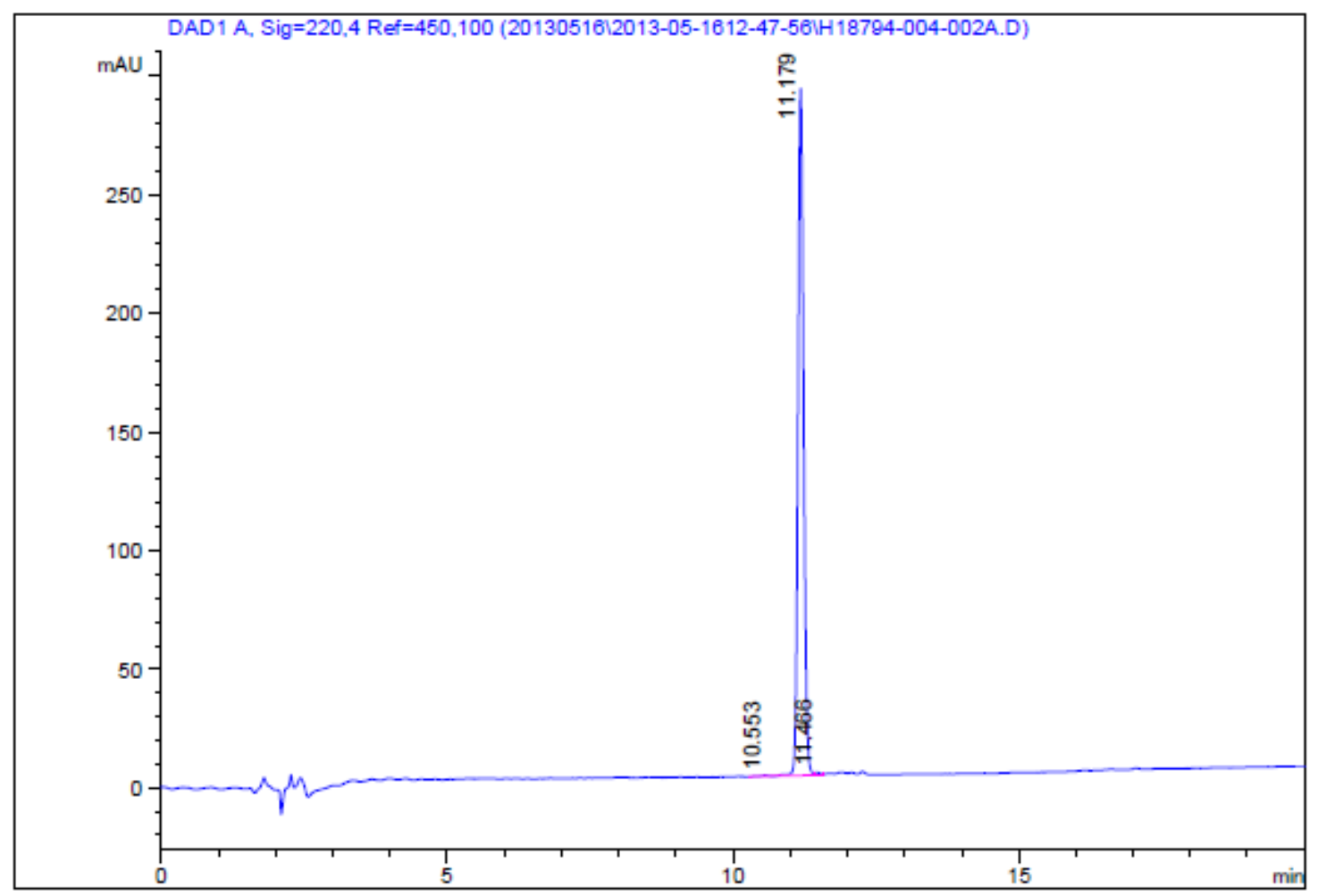

Area Percent Report

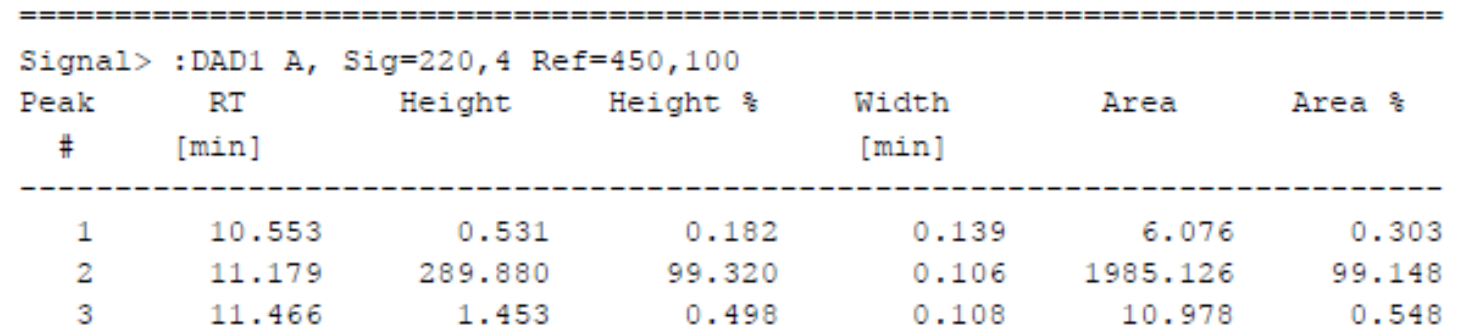

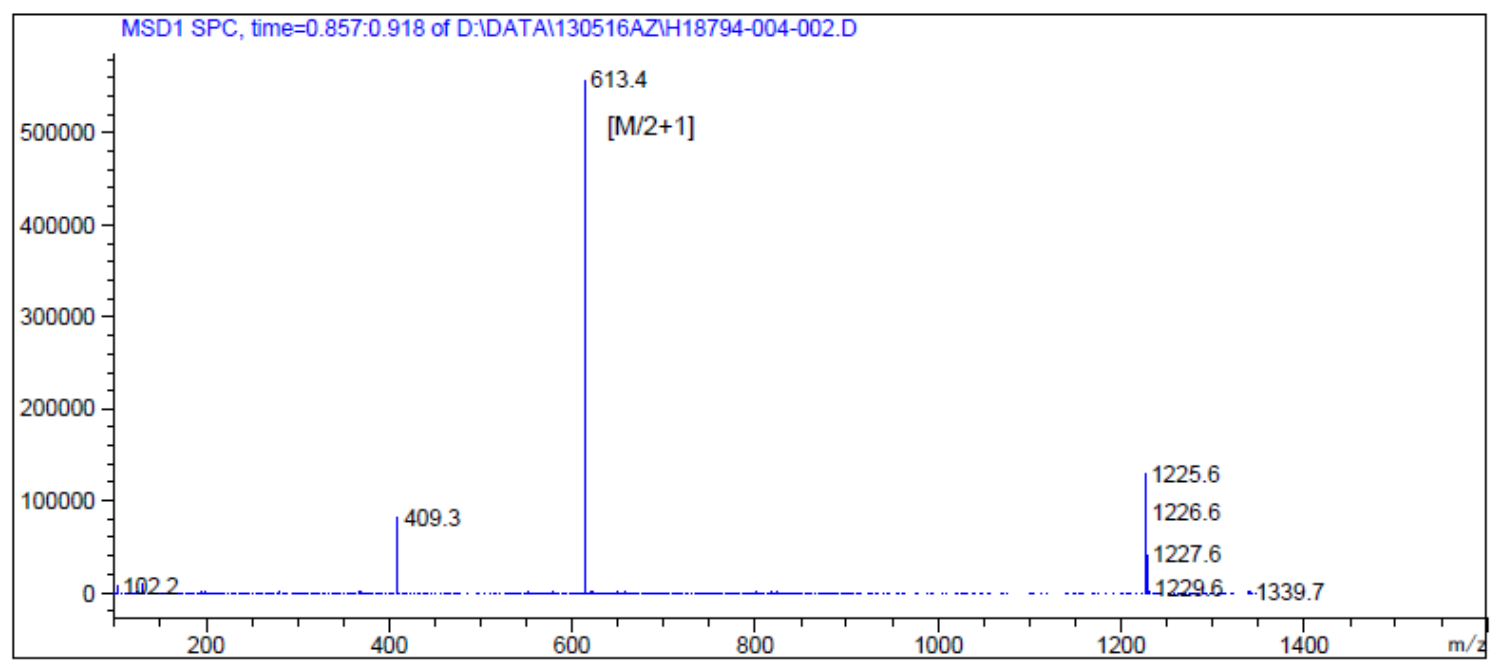




\section{Peptide 4}

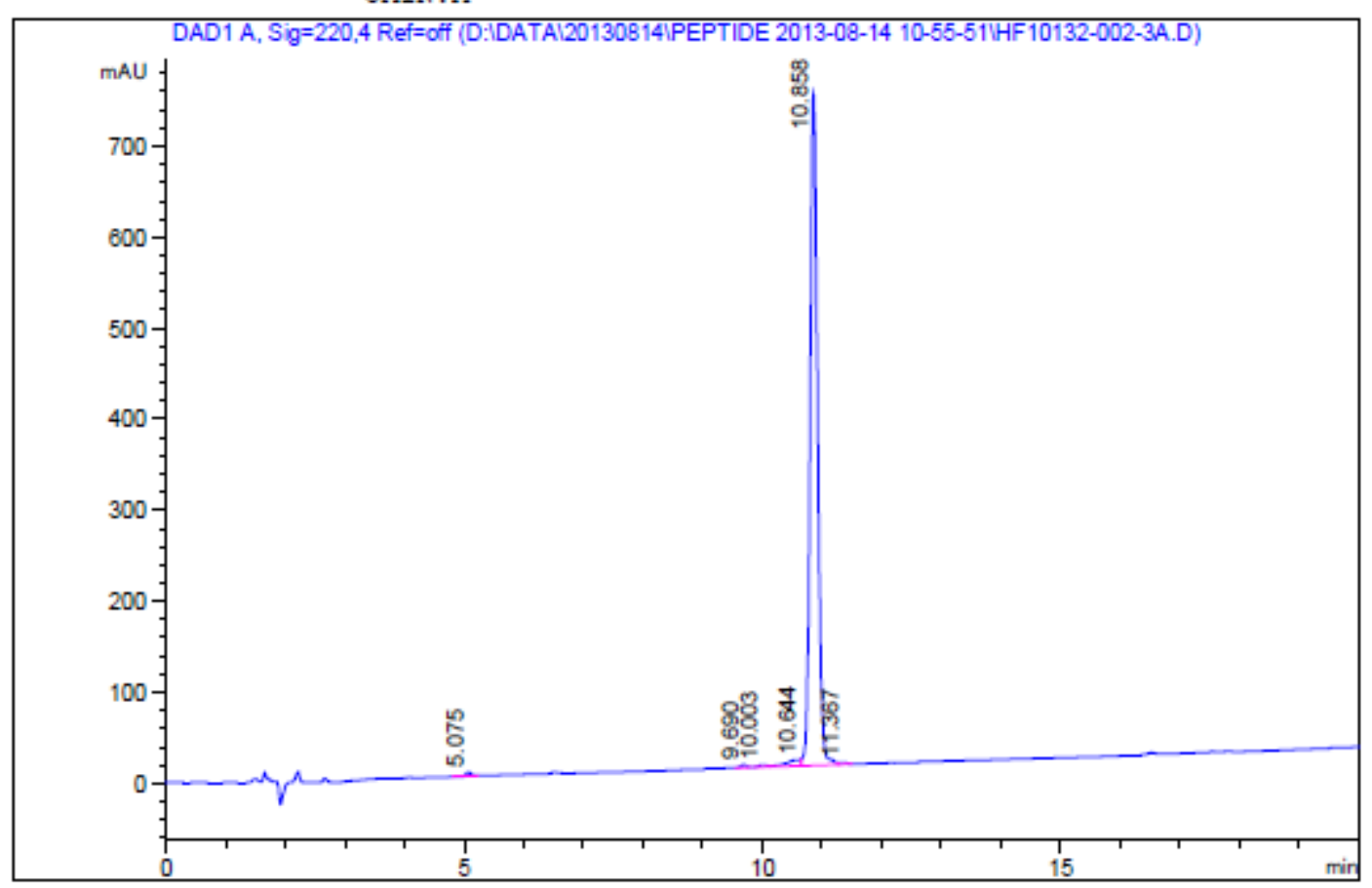

\begin{tabular}{|c|c|c|c|c|c|c|}
\hline \multicolumn{7}{|c|}{ le=e=" Area Percent Report } \\
\hline \multicolumn{7}{|c|}{ Signal->:DAD1 A, Sig=220,4 Ref=off } \\
\hline $\begin{array}{c}\text { Peak } \\
\quad \#\end{array}$ & $\begin{array}{l}\mathrm{RT} \\
{[\mathrm{min}]}\end{array}$ & Height & Height 웅 & $\begin{array}{l}\text { Width } \\
\text { [min] }\end{array}$ & Area & Area 옹 \\
\hline 1 & 5.075 & 4.156 & 0.549 & 0.089 & 24.504 & 0.371 \\
\hline 2 & 9.690 & 3.272 & 0.433 & 0.093 & 19.368 & 0.293 \\
\hline 3 & 10.003 & 2.208 & 0.292 & 0.131 & 19.063 & 0.289 \\
\hline 4 & 10.644 & 6.766 & 0.894 & 0.264 & 106.976 & 1.620 \\
\hline 5 & 10.858 & 737.722 & 97.528 & 0.145 & 6411.646 & 97.110 \\
\hline 6 & 11.367 & 2.301 & 0.304 & 0.136 & 20.884 & 0.316 \\
\hline
\end{tabular}

\section{User Spectra}

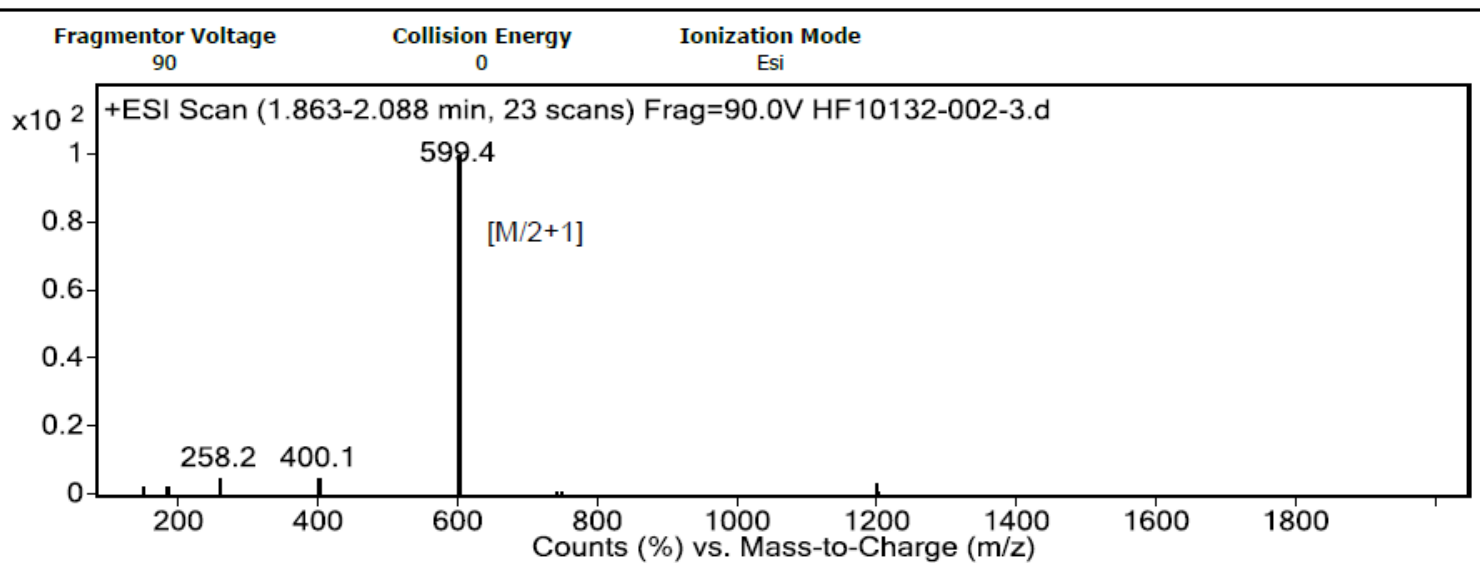




\section{Peptide 5}

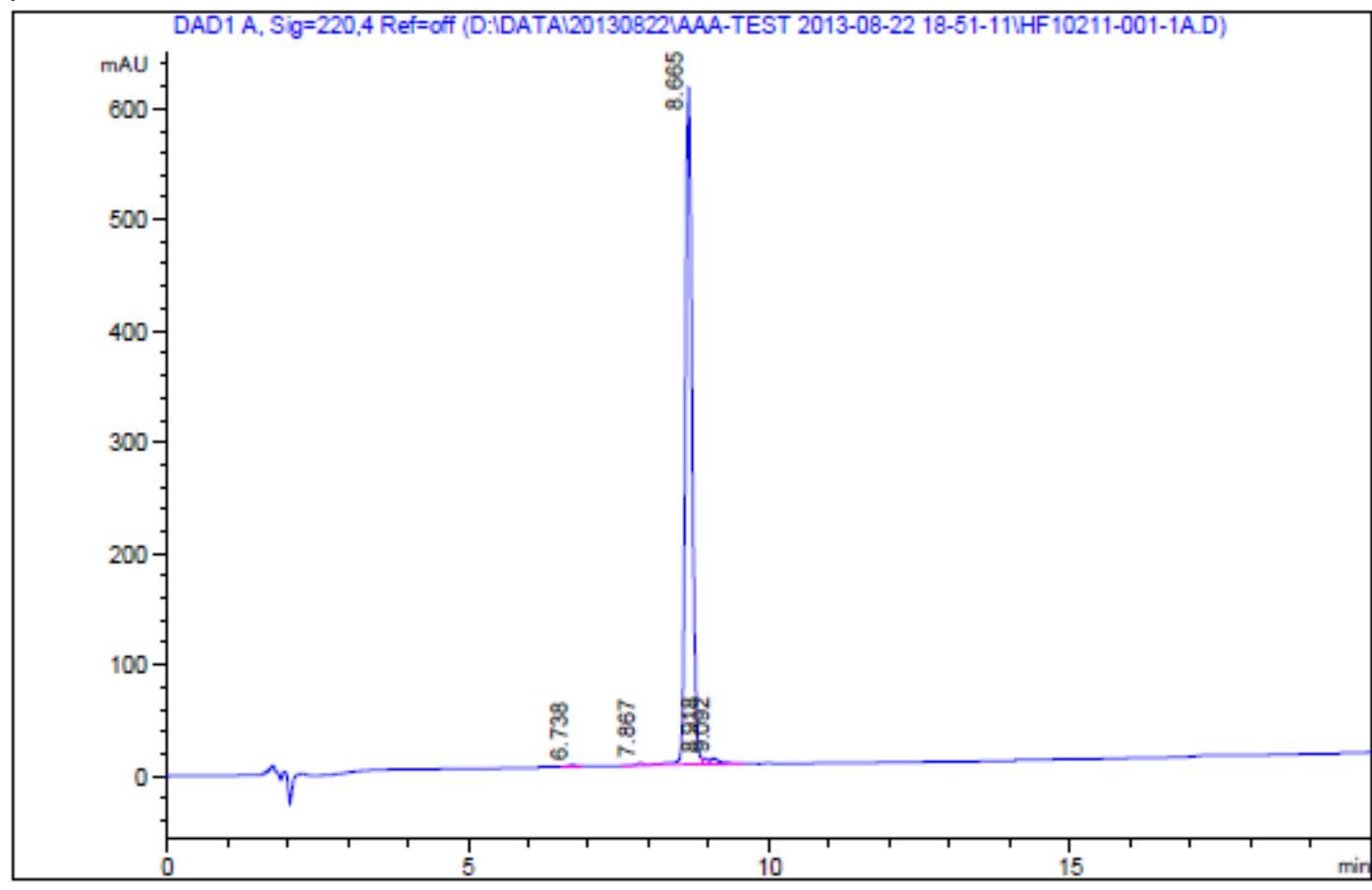

Area Percent Report

\begin{tabular}{|c|c|c|c|c|c|c|}
\hline \multicolumn{7}{|c|}{ Signal->:DAD1 A, Sig=220,4 Ref=off } \\
\hline $\begin{array}{c}\text { Peak } \\
\quad \#\end{array}$ & $\begin{array}{c}\mathrm{RT} \\
{[\mathrm{min}]}\end{array}$ & Height & Height $\frac{\text { \% }}{6}$ & $\begin{array}{l}\text { Width } \\
\text { [min] }\end{array}$ & Area & Area $\frac{8}{8}$ \\
\hline 1 & 6.738 & 1.963 & 0.315 & 0.102 & 13.197 & 0.275 \\
\hline 2 & 7.867 & 2.102 & 0.337 & 0.112 & 15.147 & 0.315 \\
\hline 3 & 8.665 & 609.646 & 97.720 & 0.120 & 4685.040 & 97.489 \\
\hline 4 & 8.918 & 5.325 & 0.854 & 0.085 & 31.325 & 0.652 \\
\hline 5 & 9.092 & 4.836 & 0.775 & 0.173 & 60.978 & 1.269 \\
\hline
\end{tabular}

User Spectra

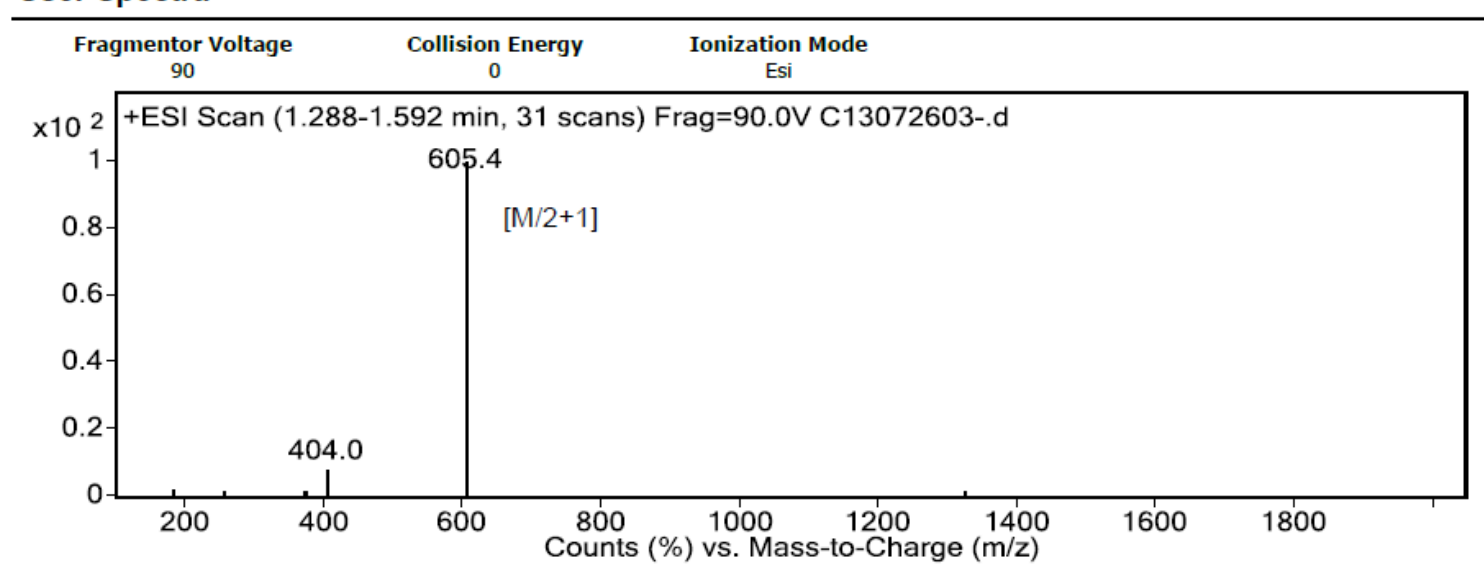




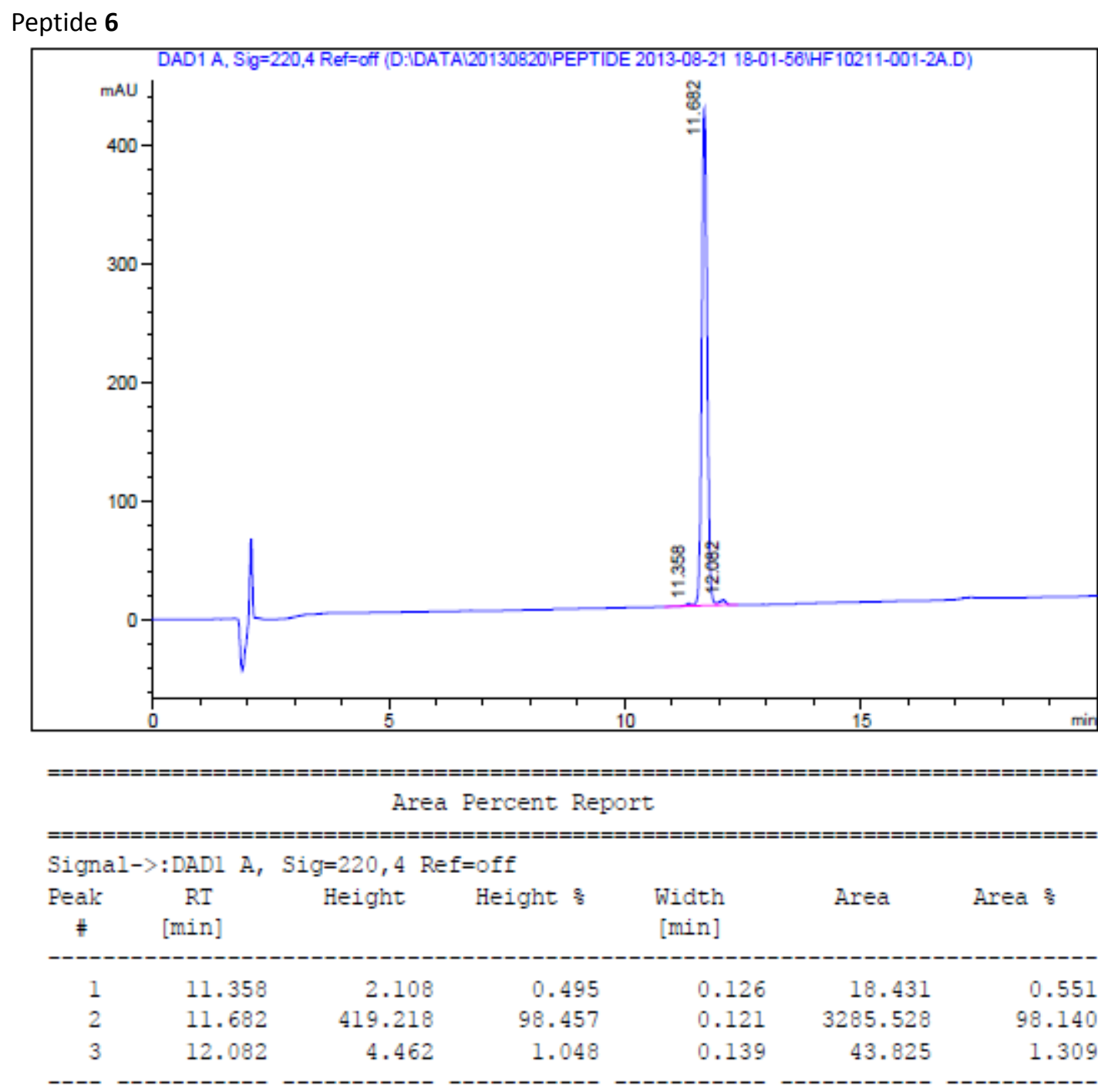

User Spectra

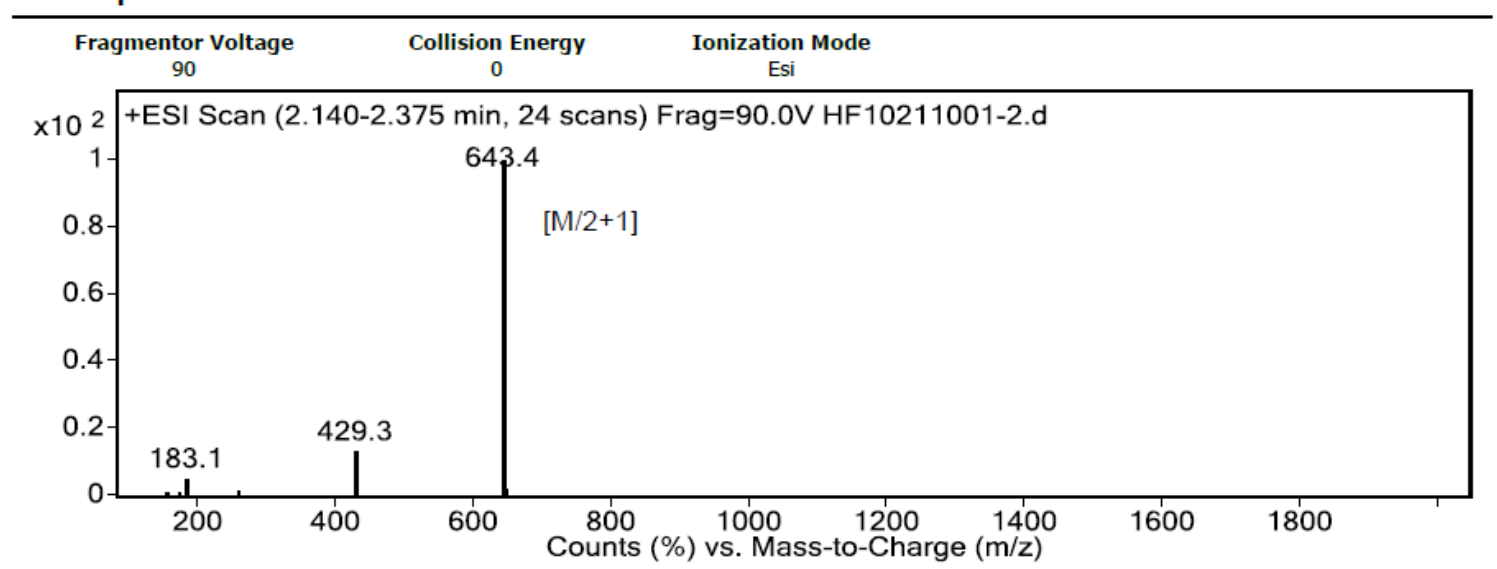




\section{Peptide 7}

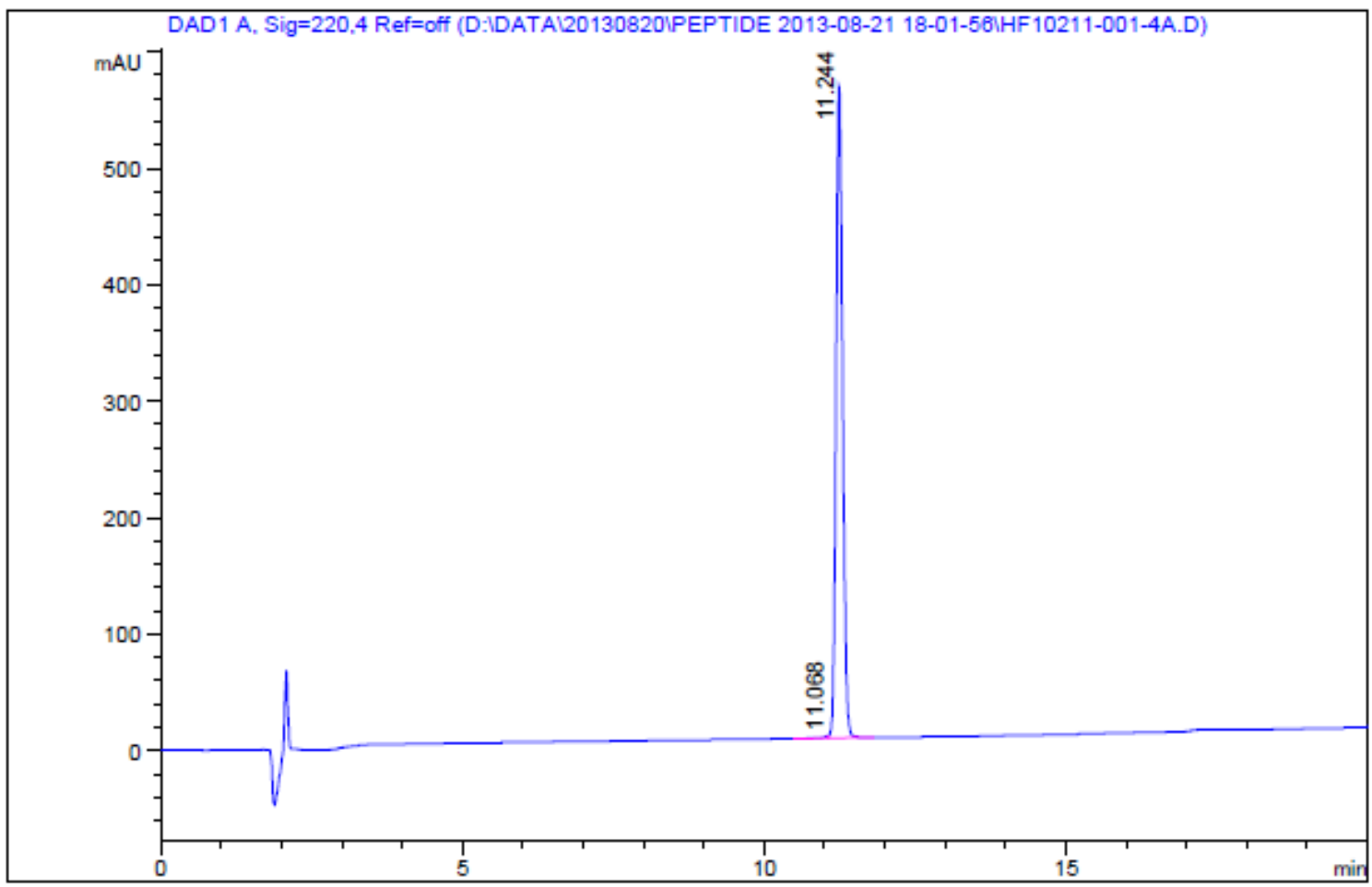

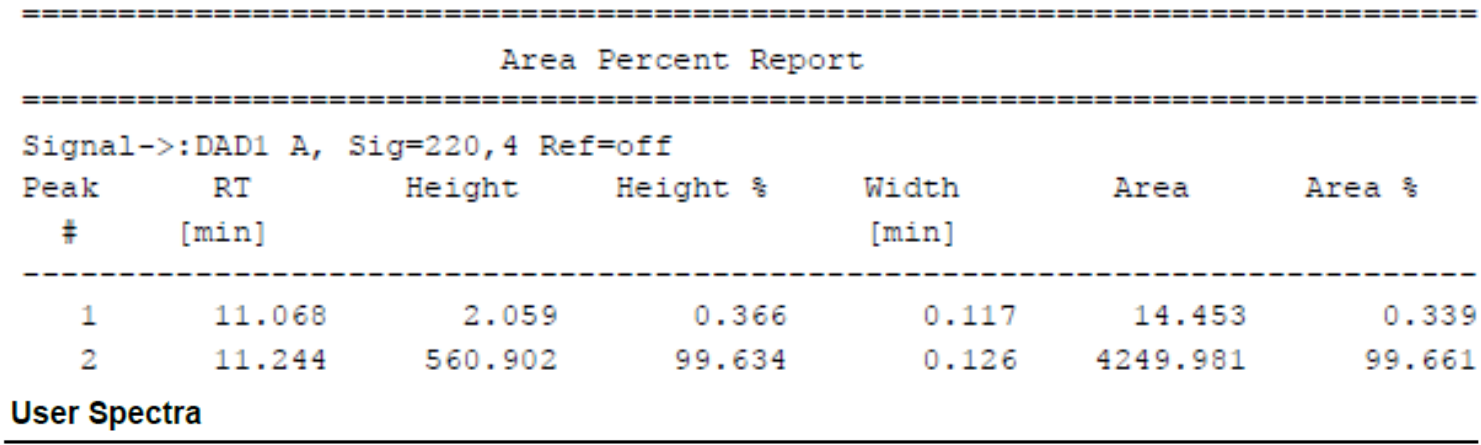

\section{User Spectra}

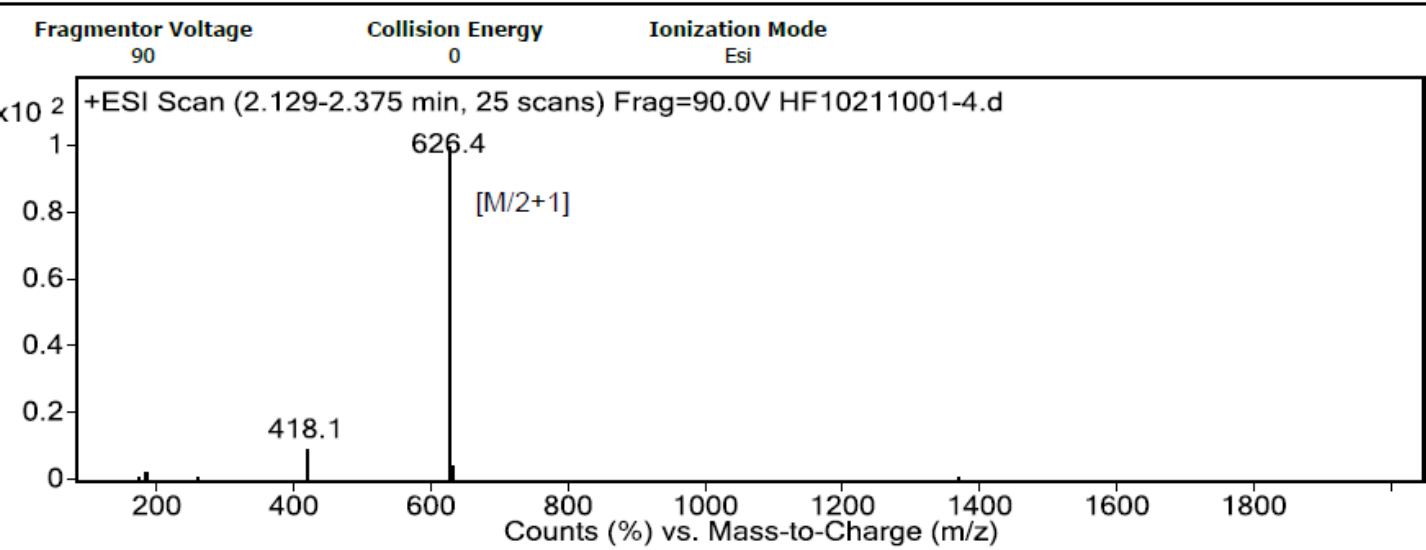




\section{Peptide 8}

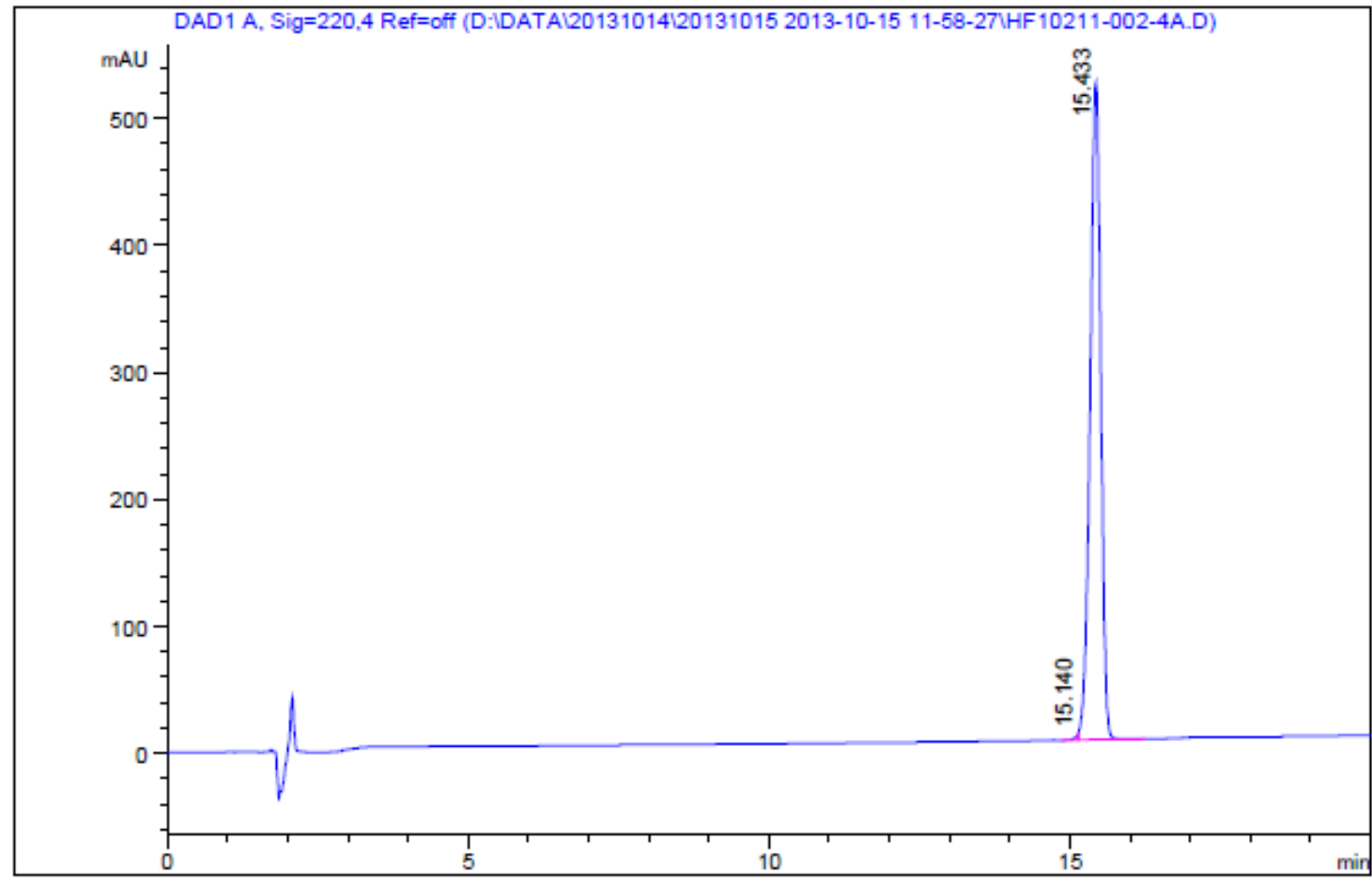

Area Percent Report

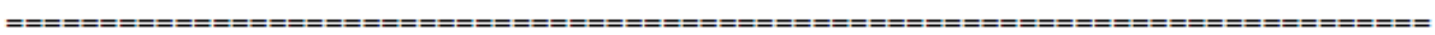

Signal->:DAD1 A, Sig=220,4 Ref=off

Peak RT Height Height \& Width Area

$\neq \quad[\mathrm{min}]$

[min]

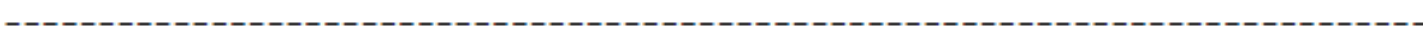

$\begin{array}{rrrrrrr}1 & 15.140 & 5.084 & 0.970 & 0.053 & 16.019 & 0.251 \\ 2 & 15.433 & 518.759 & 99.030 & 0.205 & 6365.190 & 99.749\end{array}$

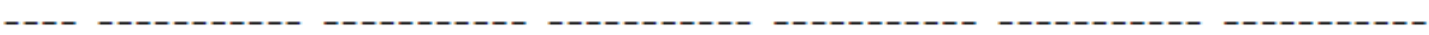

\section{User Spectra}

$90{ }^{-} 0 \quad \dot{E}_{s i}$

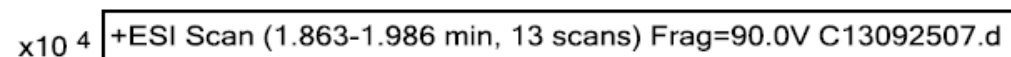

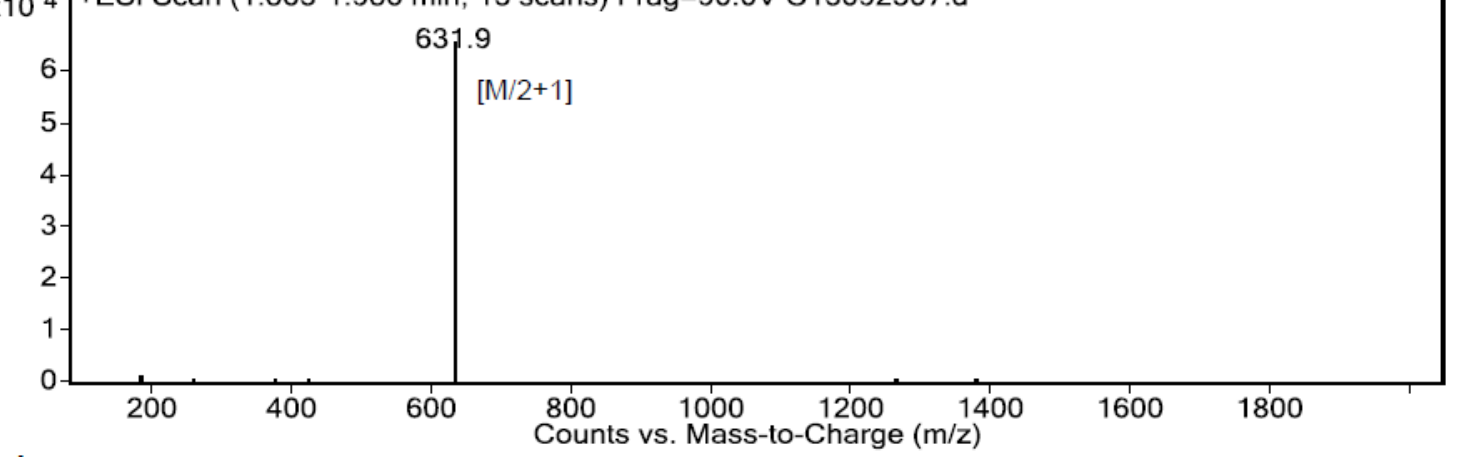




\section{Peptide 9}

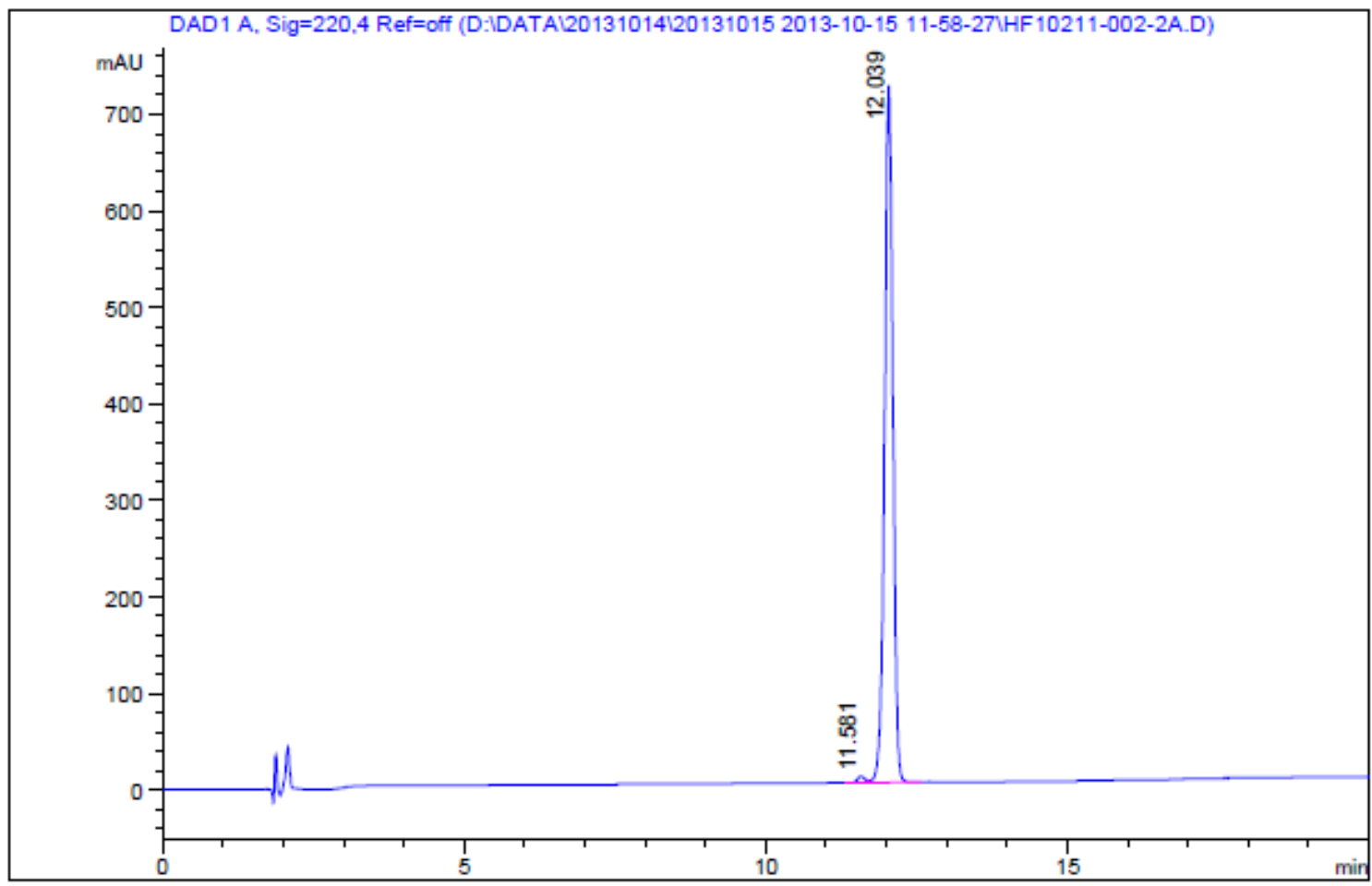

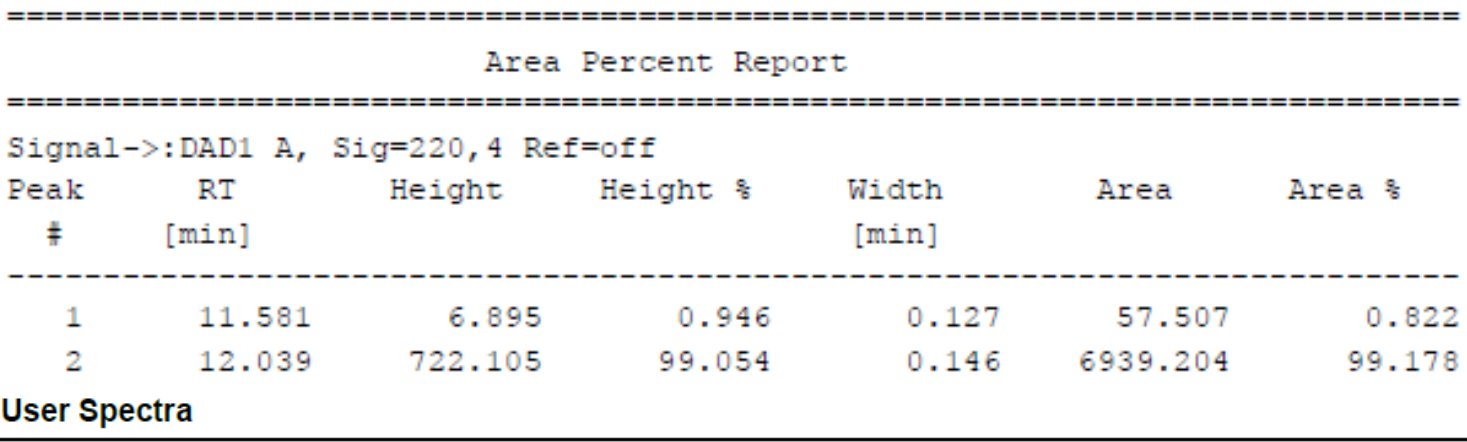

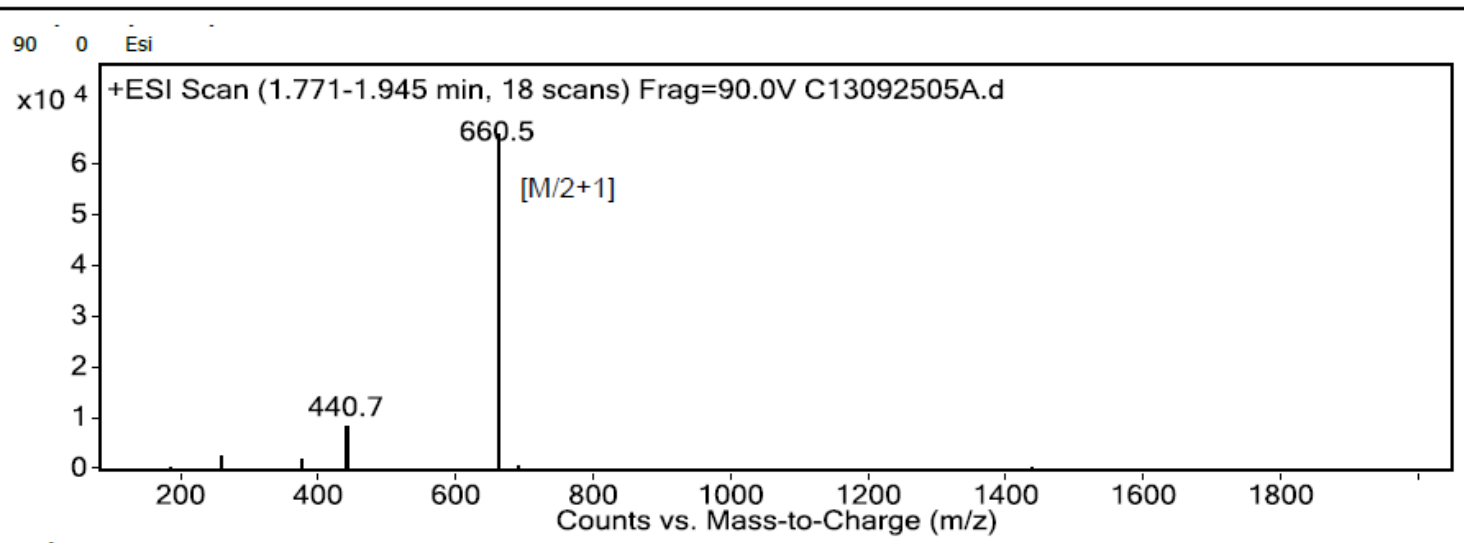




\section{Peptide 10}
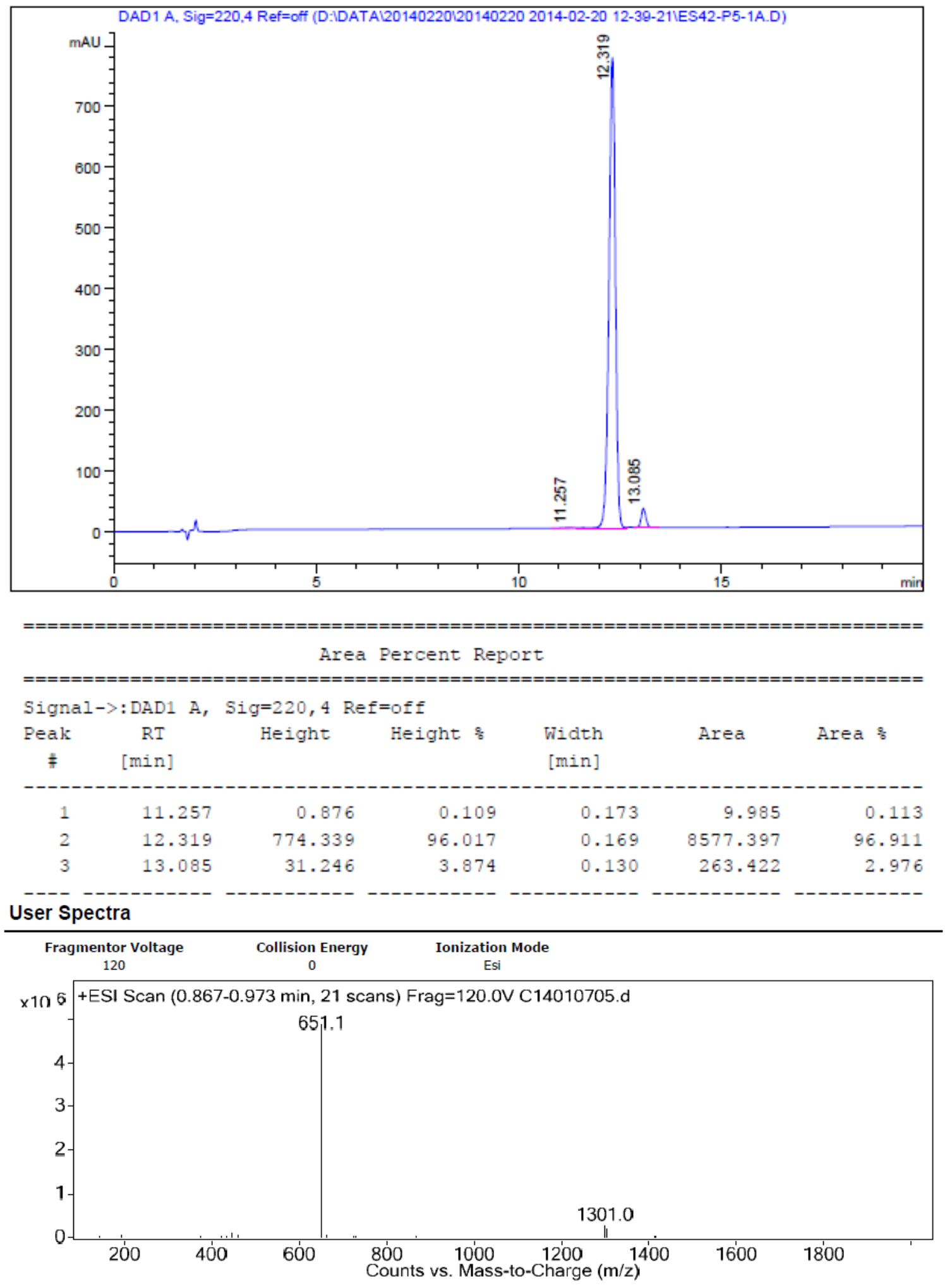


\section{References}

1. Zhao, B.; Xu, P.; Jiang, L.; Paaske, B.; Kromann-Hansen, T.; Jensen, J. K.; Sorensen, H. P.; Liu, Z.; Nielsen, J. T.; Christensen, A.; Hosseini, M.; Sorensen, K. K.; Nielsen, N. C.; Jensen, K. J.; Huang, M.; Andreasen, P. A. A Cyclic Peptidic Serine Protease Inhibitor: Increasing Affinity by Increasing Peptide Flexibility. Plos One 2014, 9, e115872. 